\title{
IMPACTO DE LAS INTERVENCIONES EN EL CENTRO HISTÓRICO DE LIMA A PARTIR DE SU DECLARACIÓN COMO PATRIMONIO CULTURAL DE LA HUMANIDAD
}

\author{
IMPACT OF INTERVENTIONS AT LIMA DOWNTOWN SINCE ITS CULTURAL HERITAGE OF HUMANITY \\ DECLARATION
}

MÓNICA RODRÍGUEZ LARRAÍN ECHECOPAR

\section{RESUMEN}

El actual grado de vigencia de la autenticidad del Centro Histórico de Lima, analizado a través de la subsistencia de los argumentos e indicadores urbanos, arquitectónicos, sociales, culturales e históricos que fundamentaron la Declaración de Patrimonio Cultural de la Humanidad, demuestra que la realidad del impacto de las intervenciones ejecutadas sobre el tejido urbano y las áreas construidas o construibles no permite acreditar resultados positivos en su conservación tras su declaración en 1991.

\section{PALABRAS CLAVE}

Autenticidad, centro histórico, impacto, patrimonio, valores.

\section{ABSTRACT}

The current impact of interventions performed on the urban tissue and either built or buildable areas, regarding the authenticity degree of the Historic Center of Lima, which is analyzed through the subsistence of urban, architectural, social, cultural and historical indicators that led to its Declaration of Cultural Heritage of Humanity, does not prove positive results in its conservation since 1991.

KEYWORDS

Authenticity, historic henter, impact, heritage, values 
El patrimonio cultural es nuestro legado del pasado, del que disfrutamos hoy y que pasamos a las futuras generaciones, siendo nuestra herencia cultural y natural, fuentes irremplazables de vida e inspiración. “... comprende las obras de sus artistas, arquitectos, músicos, escritores y sabios, así como las creaciones anónimas, surgidas del alma popular, y el conjunto de valores que dan un sentido a la vida" (UNESCO, 1982).

La Conservación de un sitio histórico, y en particular de una ciudad histórica, donde se concentra el patrimonio cultural, físico e inmaterial, no puede concebirse como mera conservación de una imagen. El desafío de su conservación consiste en asegurar al mismo tiempo su esencia como ciudad inscrita en la historia, y la continuidad de su papel como "semillero" de la innovación social, económica y cultural. (Instituto Andaluz de Patrimonio Histórico (comp.), 1999, p. 13).

Partiendo de estas premisas y considerando que la importancia de la conservación de la memoria colectiva del Centro Histórico de Lima, que es una pequeña parte del tejido urbano limeño, no se establece en la jerarquía económica o superficial sino en la identidad única y diferenciada de su simbólico espacio histórico-social, a través del tiempo se han experimentado una serie de propuestas para afrontar, desde distintas perspectivas, los procesos de conservación y restauración, los cuales han impactado sobre el tejido urbano y el patrimonio edificado. Ello ha llevado a contraer compromisos internacionales para preservar el Centro Histórico de Lima para toda la humanidad. El resultado acumulado que hoy se observa lleva a reflexionar sobre estos procesos.

Desde sus inicios, Lima virreinal ha sobrellevado una serie de cambios y ha debido superar distintos acometimientos, tanto naturales como socioculturales y económicos, que definieron una conformación singular por la cual su Centro Histórico fue declarado Patrimonio Cultural de la Humanidad ${ }^{1}$ (Figura 1). Desde entonces, sin asumir la responsabilidad que tal nominación requería, Lima y su Centro Histórico con-

1. Declaración de Patrimonio Cultural de la Humanidad del 12 de diciembre de 1991 que la UNESCO otorgó al núcleo del Centro Histórico, por la calidad estética e intrínseca de sus monumentos que determinan un patrón arquitectónico y urbanístico en América del Sur, así como por la antigüedad y permanencia de las edificaciones desde la fundación de la ciudad en 1535, el alto nivel expresivo de la técnica de construcción en adobe reforzado con ladrillo y piedra, la especifica identidad cultural expresada en la trama urbana y en la arquitectura de reinterpretación y creación local, y por la importancia histórica para América del Sur. tinuaron evolucionando y desarrollándose, pero bajo lineamientos generales, sin una efectiva planificación urbana que estuviera realmente basada en los criterios para la conservación del patrimonio que fueran establecidos en la Convención del Patrimonio Mundial de la Organización de las Naciones Unidas para la Educación, la Ciencia y la Cultura - UNESCO (WHC-03/27. $\mathrm{COM} / 7 \mathrm{~B}, 2003)$. Se abordaron los problemas inmediatos o los más agobiantes, en procesos discontinuos y sin registrar ni sistematizar las intervenciones urbanísticas ni monitorear los indicadores de los factores de riesgo patrimonial. Por ello, Lima es una ciudad carente de historiales y/o inventarios urbanísticos de su progreso y de los procesos de intervención realizados sobre su tejido urbano y, consecuentemente, sobre el de su Centro Histórico.

Por otro lado, a pesar de que aún conserva evidentes e identificables características de un singular centro histórico virreinal, los daños ocasionados por el impacto de las intervenciones ejecutadas sobre el tejido urbano y el patrimonio edificado han llevado a la pérdida de valores urbanos y a la desintegración parcial de la trama y del perfil urbano del Centro Histórico de Lima, derivando en la puesta en peligro de su autenticidad, la disminución de los valores intrínsecos en algunos de sus monumentos, la falta de reconocimiento del hecho cultural de la fusión del espíritu indígena con las corrientes europeas, la merma en permanencia y calidad de vida de la población y la falta de la afirmación de la referencia histórica, su promoción y difusión. Todo lo cual ha puesto en peligro la subsistencia de los argumentos que fundamentaron la declaración de Patrimonio Cultural de la Humanidad.

Desde que el Centro Histórico de Lima fuera nominado por la UNESCO (SC-91/CONF.002/15, 1991) hace veintidós años, persistentemente continúa advirtiéndose de su acelerado proceso de deterioro. Su pérdida no solo ocasionaría la desaparición de un extraordinario legado, sino el desvanecimiento de nuestra memoria urbana. Por ello, cabe cuestionarse ¿cómo el impacto de las inadecuadas intervenciones y el marco legal vigente han influido en el menoscabo de la autenticidad del núcleo del Centro Histórico de Lima por la pérdida de los valores de los indicadores que sustentaron su nominación al Patrimonio Cultural de la Humanidad?

El comienzo de la desvalorización del Centro Histórico está probablemente relacionado con las trans- 


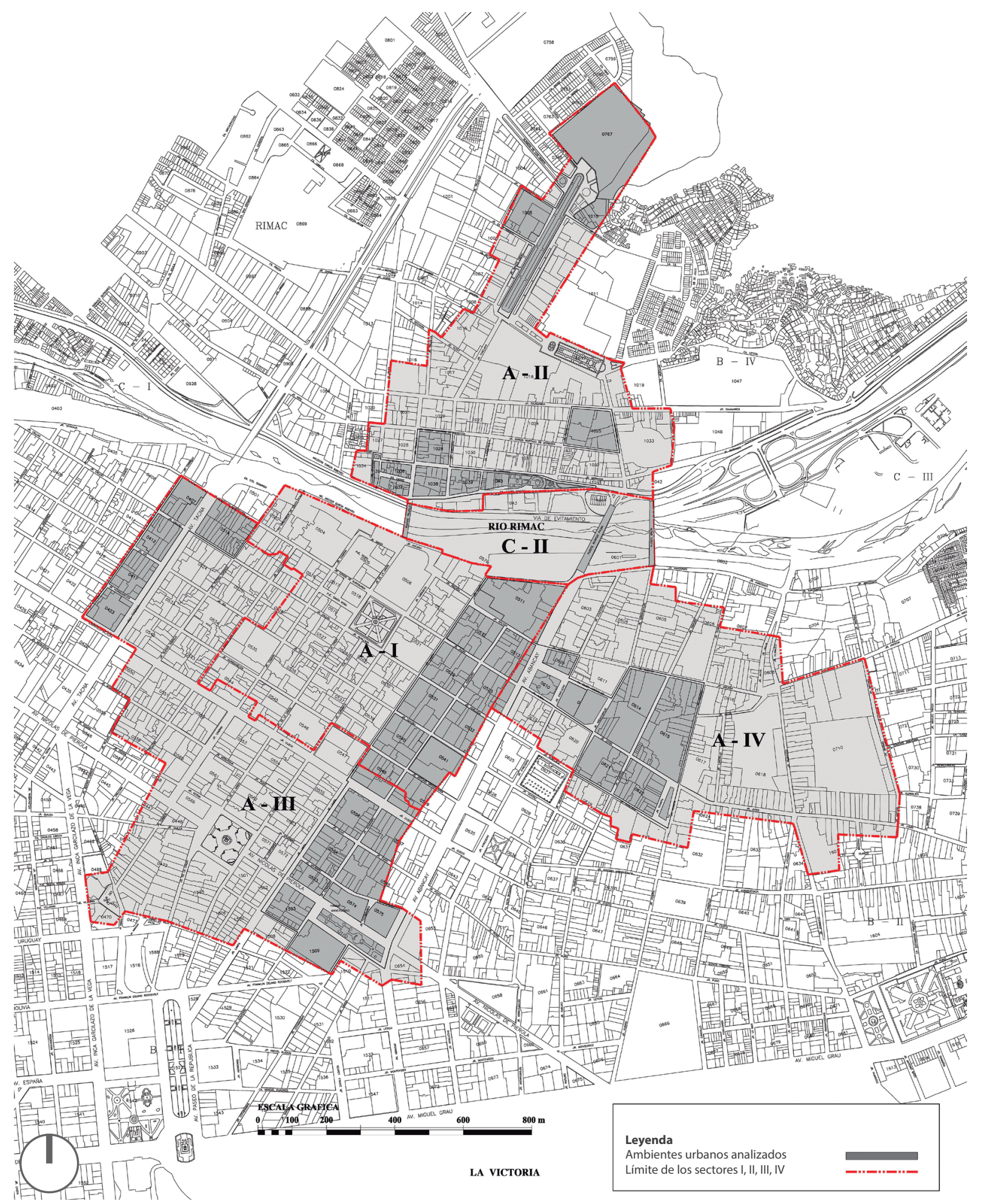

Figura 1

Plano del Área del Centro Histórico de Lima Declarada Patrimonio Cultural de la Humanidad.

Fuente: En base al plano del Instituto Catastral e Informático de Lima, octubre 1998. 


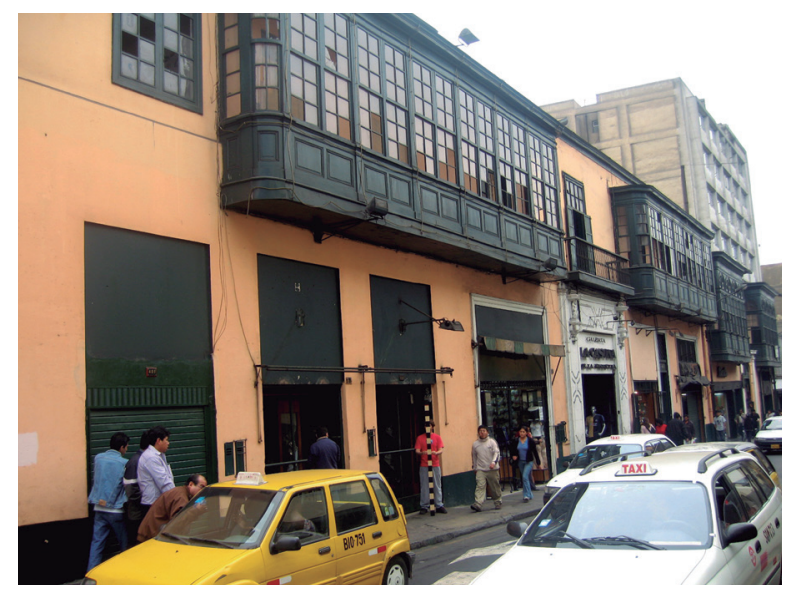

formaciones de los siglos XIX y XX orientadas a una progresiva renovación, determinando la modificación de la trama y el perfil urbano, caracterizadas por la demolición de la muralla y de gran parte de la arquitectura virreinal, la ejecución de ensanches viales y la creación de espacios urbanos inspirados en el urbanismo europeo decimonónico junto con la edificación de una nueva arquitectura, distinta a la singular del pasado y que cambió la fisonomía de la ciudad; no obstante ello, al nominarse al Centro Histórico de Lima Patrimonio Cultural de la Humanidad, tales cambios formaron parte integral de su legado histórico y configuraron un conjunto plural de estilos cronológicos con notable arquitectura que narraba la historia urbana de la ciudad.

Al darse la declaración, en 1991, una secuencia de continuos deterioros había progresado al límite de lo insostenible como corolario de la grave crisis económica precedente y de la masiva migración provinciana que convirtió al Centro Histórico en el espacio de encuentro y de servicio de los asentamientos humanos, por efecto de su crecimiento acelerado sin dotación de áreas de recreación y con escasos servicios comunales. El desgobierno, el abandono, el comercio ambulatorio, la apropiación de las vías y el caos eran la imagen más perdurable de la ciudad. Llevaron al auto-exilio de empresas comerciales representativas, instituciones tradicionales y pobladores de clase media alta. A estos problemas se les sumó el estado de violencia social y la corrupción gubernamental.

Por iniciativa del recién fundado Patronato de Lima y a través de la UNESCO, se logra el compromiso de recuperar el Centro Histórico de Lima y de conservar

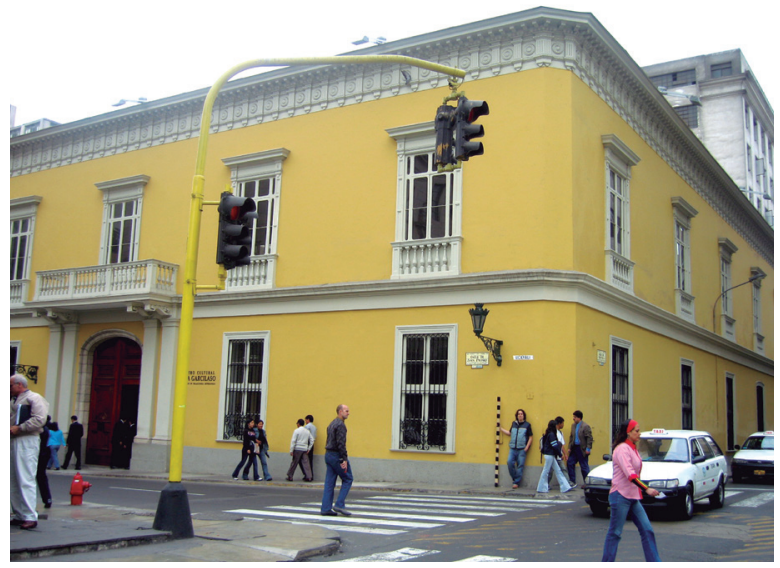

o enriquecer los valores que llevaron a su designación universal. Si bien, hubo normas fundamentales como la Ordenanza Municipal No 062 (Municipalidad Metropolitana de Lima, 1994) y la Ley Orgánica de Municipalidades N 27972 (Congreso de la República del Perú, 2003) e intervenciones muy positivas como la recuperación de la operatividad y funcionalidad urbana (inexistente en 1991) y la reubicación de los ambulantes, durante la gestión del Sr. Alberto Andrade Carmona; también hubo numerosas normas e intervenciones con impactos negativos e irrecuperables que ponen en peligro su autenticidad y nuestra memoria urbana.

El Estudio del Impacto de las Intervenciones en el Núcleo del Centro Histórico de Lima, a partir de la Declaración de Patrimonio Cultural de la Humanidad (Rodríguez Larraín, 2012), advirtió que en el transcurso de los años 1991 a 2010, los inmuebles habían sufrido diversas modificaciones que afectaron la autenticidad de su arquitectura, diseño y materiales. Se habían impactado en forma irrecuperable el 8.57\% de las construcciones (sin incluir las edificaciones demolidas que no habían podido ser cuantificadas) y se habían visto seriamente afectadas el $26.42 \%$ de estas, por la destrucción de los estratos históricos, el reemplazo de elementos originales y la adición de nuevos elementos. Asimismo, el $26.71 \%$ se hallaba amenazado por intervenciones con impactos negativos menores, producto principalmente de la falta de mantenimiento y prevención. Estos impactos habían afectado en forma distinta a cada una de las zonas, siendo el Rímac el que presentaba mayores impactos negativos irreversibles y el menor número de inter- 


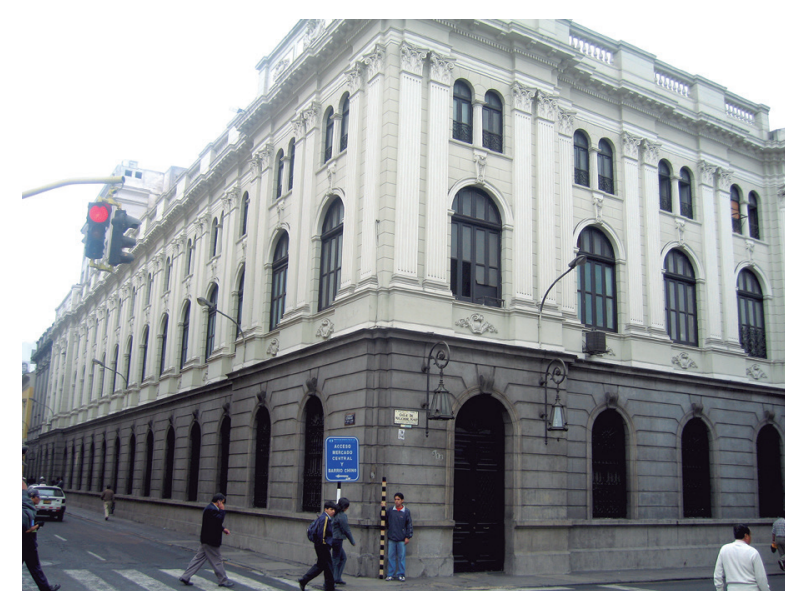

venciones positivas y la zona del núcleo fundacional la que tenía menores impactos negativos irreversibles y el mayor número de intervenciones positivas.

De los inmuebles analizados en el núcleo fundacional, el $47.99 \%$ de la construcción (sobre el $32.98 \%$ de área construible) había tenido intervenciones con impacto positivo y el resto de las intervenciones habían sido negativas, habiendo tenido el $23.31 \%$ impactos menores, el $22.48 \%$ impactos recuperables y el $6.22 \%$ impactos irrecuperables. Los valores arquitectónicos perdidos correspondían a casonas monumentales demolidas, total o parcialmente y que hoy permanecen como locales tipo galerías o feriales, playas de estacionamiento o callejones. Igualmente, estaban relacionados con las casonas demolidas, dejando solo el muro fachada, y reemplazadas por galerías con pequeños locales inadecuados y en deterioro, como la Galería El Rey de Lima; con casonas en mal estado que presentaban estructuras colapsadas en peligro de derrumbe como el predio ubicado en el Jr. Huallaga 461-465-467-471 o como el que hasta el 2010 existió en el Jr. Junín 300-304-316 esquina con el Jr. Lampa 305-319; y con monumentos ampliados o restaurados de forma incorrecta que habían transformado las características originales de estos, como la Galería El Palacio y la Casona de la Virreyna (Figura 2) y La Casona. Por otro lado, el estudio estableció que entre los inmuebles cuyos valores arquitectónicos habían sido recientemente recuperados destacaban la restauración de la Casa Aspíllaga (Figura 3), del antiguo Banco del Perú y Londres (Banco Popular del Perú) hoy Edificio Luis Alberto Sánchez (Figura 4), y de la Casa Negreiros. Asimismo, que sobresalían la

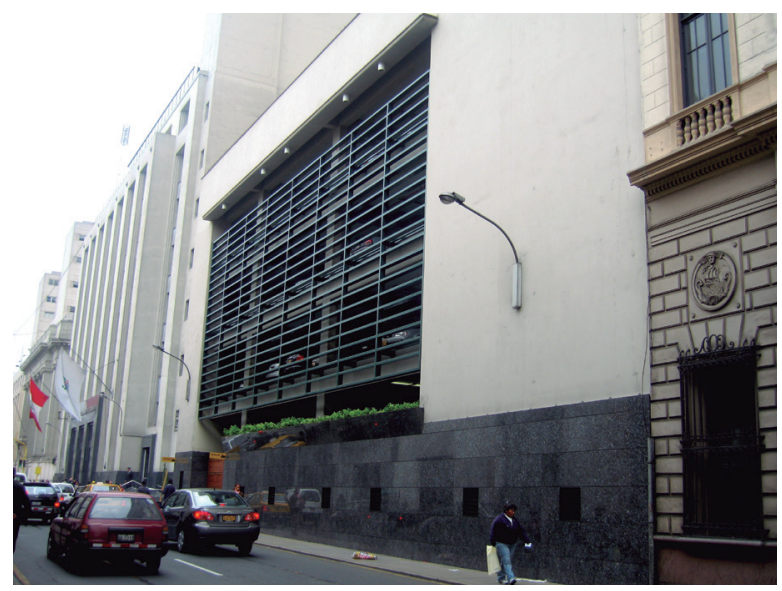

De izquierda a derecha:

Figura 2 (página anterior)

Casona de la Virreyna, Jr. Huallaga 458-460-462-466, Lima Cercado.

Figura 3 (página anterior)

Casa Aspíllaga, Jr. Ucayali 391 esquina con Jr. Azángaro, Lima Cercado.

Figura 4

Antiguo Banco del Perú y Londres, Jr. Huallaga 350 a 398 esquina con Jr. Azángaro 364-370, Lima Cercado.

Figura 5

Edificio de estacionamiento del Ministerio de Relaciones Exteriores, Jr. Lampa 559-561, Lima Cercado. 

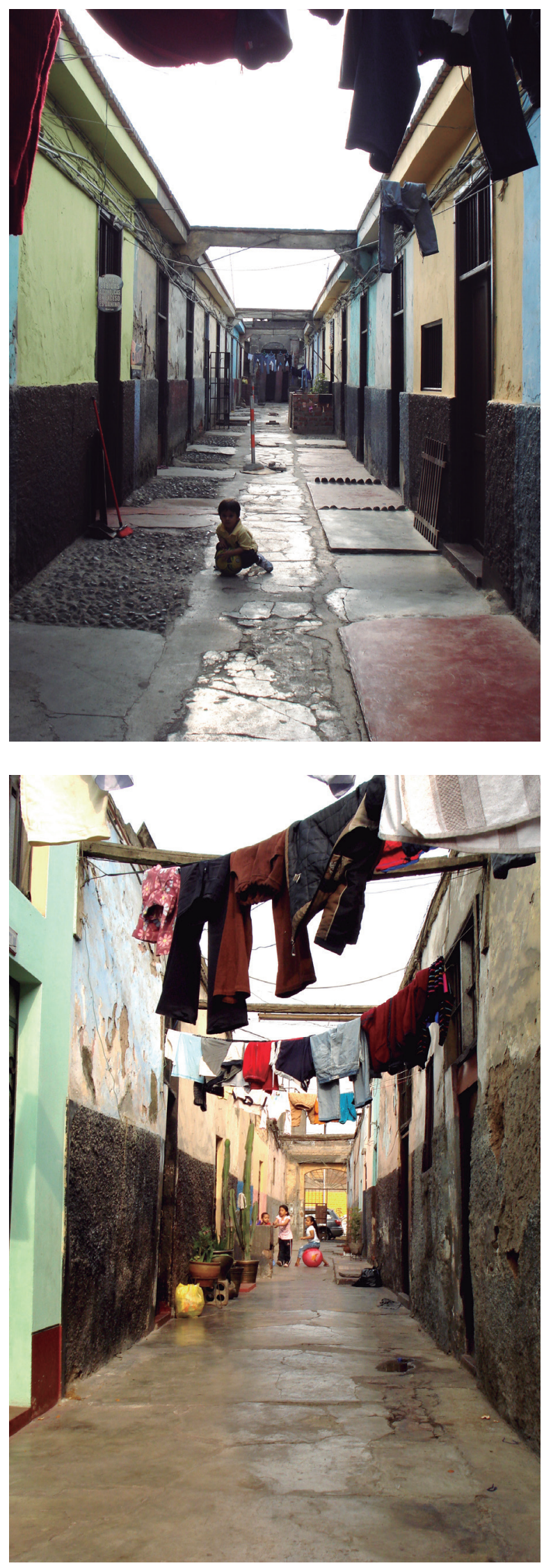

puesta en valor del antes edificio administrativo del Banco Popular del Perú (Jr. Azángaro 374-376-380) y del actual edificio de oficinas del Reniec (Jr. Áncash 336-340-344); el reciclaje con obra nueva del edificio ubicado en la esquina de los jirones Jr. Azángaro 450 y Ucayali; y la inclusión de arquitectura moderna integrada al entorno patrimonial como el edificio de estacionamiento del Jr. Lampa 559-561 (Figura 5).

Con relación al sector del Rímac, el estudio (Rodríguez Larraín E., 2012) concluyó que solo el 19.41\% de la construcción (sobre el $41.00 \%$ de área construible) habían tenido intervenciones con impacto positivo y que el resto de las intervenciones habían sido negativas, habiendo tenido el $28.87 \%$ impactos menores, el $34.84 \%$ impactos recuperables y el $16.88 \%$ impactos irrecuperables. Los valores arquitectónicos perdidos correspondían a casas del antiguo barrio obrero ampliadas en forma desigual, a inmuebles de los siglos XIX y XX que hallándose tugurizados y en mal estado habían sido total o parcialmente transformados con demoliciones de muros, cambios en las proporciones de sus vanos y algunas con la adición de callejones o corralones igualmente tugurizados (Figura 6). Correspondían, asimismo, a corralones precarios, tugurizados o inaccesibles (Figura 7) o a secciones de inmuebles subdivididos y demolidos para construir unidades independientes de tipo autogestionario y sin valor. Por otro lado, entre las fincas cuyos valores arquitectónicos habían sido últimamente reconstruidos destacaban las ubicadas en la esquina del Pasaje Canas y el Jr. Trujillo y en el Jr. Trujillo 240.

Con relación a Monserrate y los alrededores de la Av. Tacna, del Jr. Cailloma, de la Plaza San Martín y del Parque Universitario, el estudio determinó que el $38.66 \%$ de la construcción (sobre el 30.69\% de área construible) habían tenido intervenciones con impacto positivo y el resto de la intervenciones habían sido negativas, habiendo tenido el $23.76 \%$ impactos menores, el $27.43 \%$ impactos recuperables y el $10.15 \%$ impactos irrecuperables. Los valores arquitectónicos perdidos en este sector correspondían a inmuebles total o parcialmente perdidos o alterados (Figuras 8 y 9), a casonas monumentales alteradas (Figura 10) o demolidas dejando la primera crujía y permaneciendo como playas de estacionamiento y/o reemplazados por falsos históricos o reconstrucciones de mala calidad. También se incluyen casonas monumentales a las que se le habían adicionado volúmenes que desfiguraban su conformación original, con galerías comerciales con instalaciones clandestinas o 

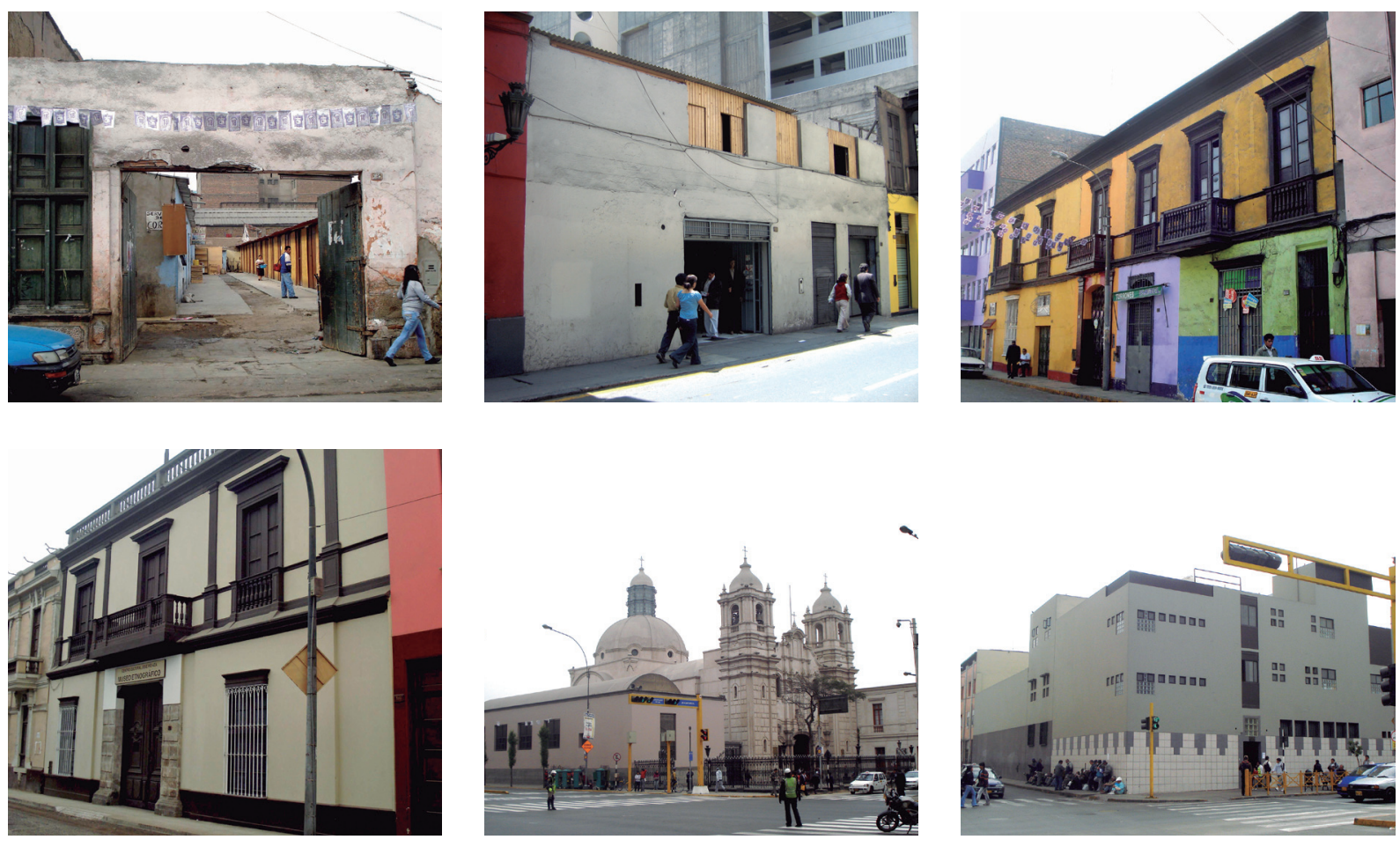

con locales no adecuados con alto riesgo (corredores estrechos, mercaderías en pasillos, instalaciones deficientes y otros), y/o construcción no acorde con el Centro Histórico como la recién inaugurada Galería Ciudad de los Reyes. Por otro lado, también indicaba que entre los inmuebles cuyos valores arquitectónicos habían sido recientemente recuperados destacaban la restauración integral y adecuación a nuevo uso de la Casona de la Universidad Nacional Mayor de San Marcos, la restauración de la Casa de los Pianos y su acondicionamiento a Museo Etnográfico y Centro Cultural José Pio Aza, Callao 562 (Figura 11) y la restauración de la bóveda y el altar mayor de la Iglesia de la Santísima Trinidad y de los ambientes, muebles y obras artísticas del Monasterio de Nazarenas Carmelitas Descalzas (Figura 12). También sobresalía la integración al entorno del Centro Médico Señor de los Milagros (Figura 13). Finalmente, se mencionaba como acción positiva la compra de terrenos baldíos y/o inmuebles deteriorados o abandonados por parte del Monasterio de Nazarenas Carmelitas Descalzas, para construir el Museo del Señor de los Milagros o integrarlos al lote del monasterio.

Con relación a Barrios Altos, el estudio demostró que solo el $27.48 \%$ de la construcción (sobre un $21.51 \%$
De izquierda a derecha y de arriba a abajo:

Figura 6 (página anterior)

Jr. Hualgayoc 367-371-375-377-sn, Lima Cercado.

Figura 7 (página anterior)

Jr. Cajamarca 450 a 498 esquina con Jr. Hualgayoc 381 a 399, Lima Cercado.

Figura 8

Jr. Ica 587, Lima Cercado, Jr. Azángaro 557-563-567-573, Lima Cercado.

Figura 9

Jr. Azángaro 543-545-549, Lima Cercado.

Figura 10

Jr. Chancay 467 a 489, Lima Cercado.

Figura 11

Casa de los Pianos, Callao 562 (antes 574), Lima Cercado.

Figura 12

Monasterio de Nazarenas Carmelitas Descalzas Jr. Huancavelica 507-515 esquina con Av. Tacna 456-462 y Av. Emancipación 516 a 580, Lima Cercado.

Figura 13

Centro Médico Señor de los Milagros, Av. de la Emancipación 594 esquina con Jr. Chancay, Lima Cercado. 
de área construible) había tenido intervenciones con impacto positivo y el resto de las intervenciones habían sido negativas, habiendo tenido el $37.78 \%$ impactos menores, el $28.44 \%$ impactos recuperables y el 6.30\% impactos irrecuperables. Asimismo, que los valores arquitectónicos perdidos en Barrios Altos correspondían a monumentos virreinales de arquitectura civil demolidos, en forma total o parcial, para permanecer como terrenos baldíos o para construir galerías o locales que dejando el muro fachada o la primera crujía han sido demolidos y reemplazados por construcciones modernas, generalmente de mala calidad, destinadas a servicios comerciales para una población de nivel socioeconómico medio o medio inferior; como en el caso de las Galerías Juan de Dios, y otras (situación que se agravaba si se sumaban las ejecutadas antes de 1991, como la Galería El Carmen). Igualmente, se incluyen inmuebles patrimoniales del siglo XIX que hallándose tugurizados y en mal estado habían sido total o parcialmente transformados con demoliciones de muros y cambios en las proporciones de sus vanos y con la adición de callejones o corralones (también tugurizados) o edificios de hasta cuatro pisos sobre una pequeña sección, quedando desfigurados y alterados en forma permanente, como la Quinta Trinitarias y otros (Figuras 14 y 15); y a casonas monumentales en mal estado que fueron abandonadas hasta su total destrucción como la ruina que existió hasta el 2010 en la esquina del Jr. Ancash 520-528 con la Av. Abancay 203-205 o que presentan estructuras colapsadas como los inmuebles del Jr. Huanta 518-522-526-530, 553-556 (Figura 16) y 606. Por otro lado, entre los inmuebles cuyos valores arquitectónicos habían sido recientemente recuperados destacaban las restauraciones con obra nueva de la Casa Nacional de Moneda y del Palacio Legislativo (Figura 17) y la restauración de la Casa de las Trece Monedas y su adecuación a Museo Nacional Afro Peruano (Figura 18). Igualmente sobresalía la integración del edificio Víctor Raúl Haya de la Torre al entorno (Figura 19).

En general, los daños ocasionados por el impacto de las intervenciones se observan en el estado mayoritariamente deficiente de las propiedades, la aparición de inmuebles precarios o de tipo autogestionario, el reemplazo de los muros de adobe y/o quincha por ladrillo y/o concreto y el estado de deterioro avanzado
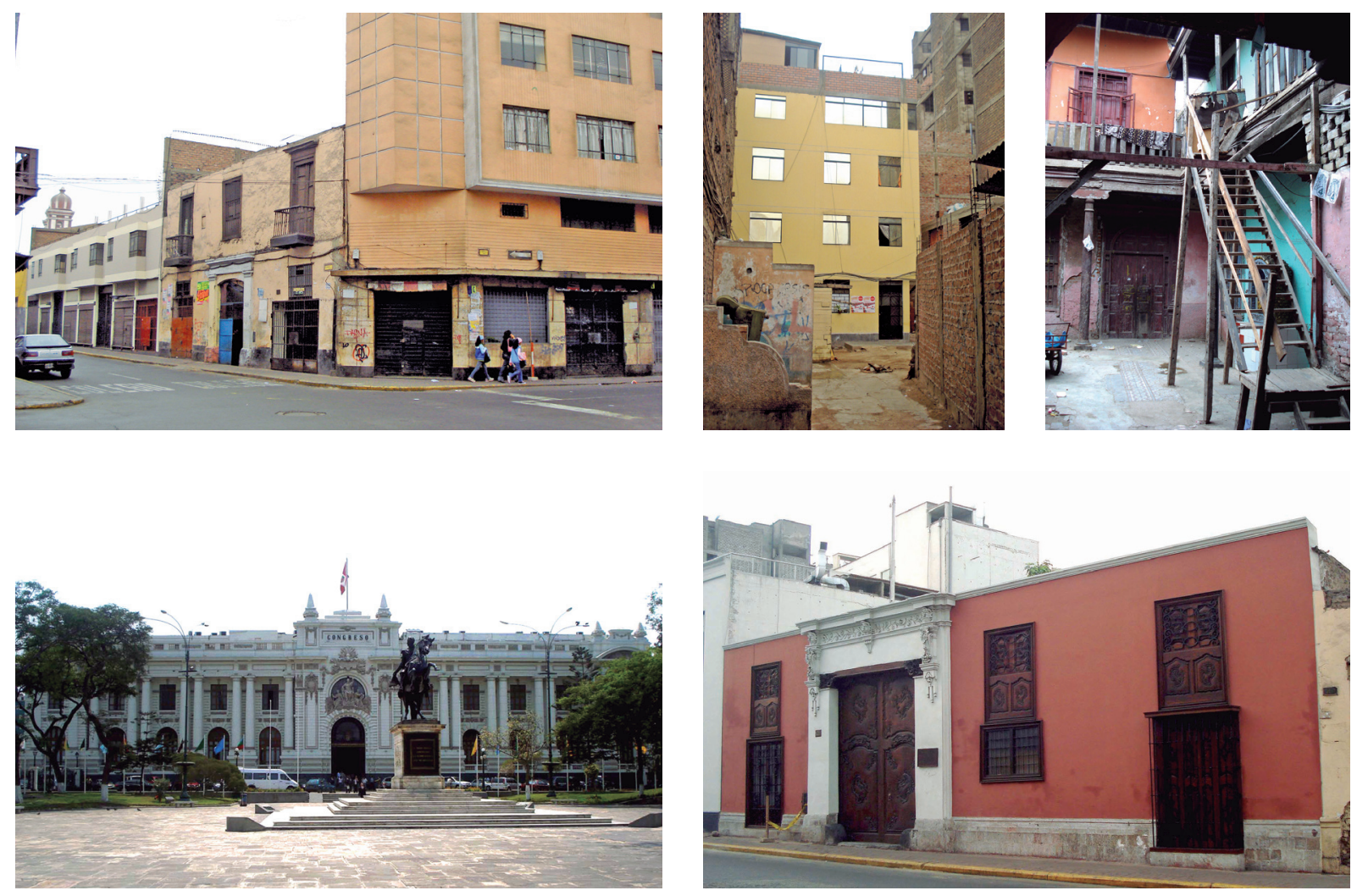
de las casonas patrimoniales con valor excepcional universal, cuyos méritos intrínsecos se hallan amenazados por la destrucción de los estratos históricos, el reemplazo de elementos originales y la adición de nuevos elementos ajenos (Figura 20), contribuyendo prioritariamente a la desvalorización del Centro Histórico. Si bien la economía ha mejorado notablemente y, por ende, el mantenimiento de los edificios lo hará también a corto plazo, la situación de las casonas patrimoniales es diferente. No se trata solo del desinterés en rescatarlas sino que estas constituyen el medio propiciatorio para la ejecución de juicios de desalojo a inquilinos precarios, logrando así la recuperación de estos inmuebles para actividades comerciales que generan mayor renta, pero con un sobreuso que deteriora igual o más que la tugurización. Por ello, deberían ser declaradas bienes de utilidad y necesidad pública, permitiéndose que sean objeto de expropiación, al hallarse en peligro de perder sus valores intrínsecos y, por ende, su autenticidad, aspecto decisivo en la valoración de los bienes culturales para integrar la Lista del Patrimonio Mundial (Congreso de la República del Perú, 2004).

De izquierda a derecha y de arriba a abajo:

Figura 14 (página anterior)

Quinta Trinitarias, Jr. Áncash 706-708-710 Barrios Altos, Lima Cercado.

Figura 15 (página anterior)

Quinta Trinitarias, interior, Jr. Áncash 706-708-710 Barrios Altos, Lima Cercado.

Figura 16 (página anterior)

Jr. Huanta 553-556, Barrios Altos, Lima Cercado.

Figura 17 (página anterior)

Palacio Legislativo, Jr. Junín esquina con Jr. Ayacucho 279 y Jr. Andahuaylas 450 Barrios Altos, Lima Cercado.

Figura 18 (página anterior)

Casa de las Trece Moneda, Jr. Áncash 542, Barrios Altos, Lima Cercado.

Figura 19

Edificio Víctor Raúl Haya de la Torre, Jr. Áncash 544 esquina con Jr. Ayacucho y calle Simón Rodríguez.

Figura 20

Jr. Trujillo 224 a 234, Rímac.

Figura 21

Estación Unión (Servicio Norte) del Metropolitano, Lima Cercado.
Lo expuesto evidencia que no existe efectividad en la aplicación del marco legal para la protección y recuperación de los valores arquitectónicos, habiéndose afectado la antigüedad, la autenticidad y la permanencia de las edificaciones propias de la arquitectura civil doméstica. Asimismo, que los deterioros en las edificaciones de valor histórico monumental que se encuentran tugurizadas, han avanzado al grado del colapso de los servicios y las estructuras. Se ha imbricado con ello una seria amenaza al valor relacionado con la fusión del espíritu indígena y las corrientes europeas expresada en la arquitectura de reinterpretación y creación local, y la permanencia de la tipología constructiva tradicional del abobe.

En cuanto al análisis de los valores urbanos, el estudio (Rodríguez Larraín E., 2012) indicó que si bien últimamente no se han realizado ensanches a las calles, la trama urbana se ha visto afectada por la reciente pérdida de predios edificables a favor de áreas libres recreacionales (como el Parque de la Cultura, la Plaza de la Nación o la Plazuela del Teatro Municipal) y por la innecesaria inclusión de paraderos para El Metropolitano, dando como resultado la ruptura del te-
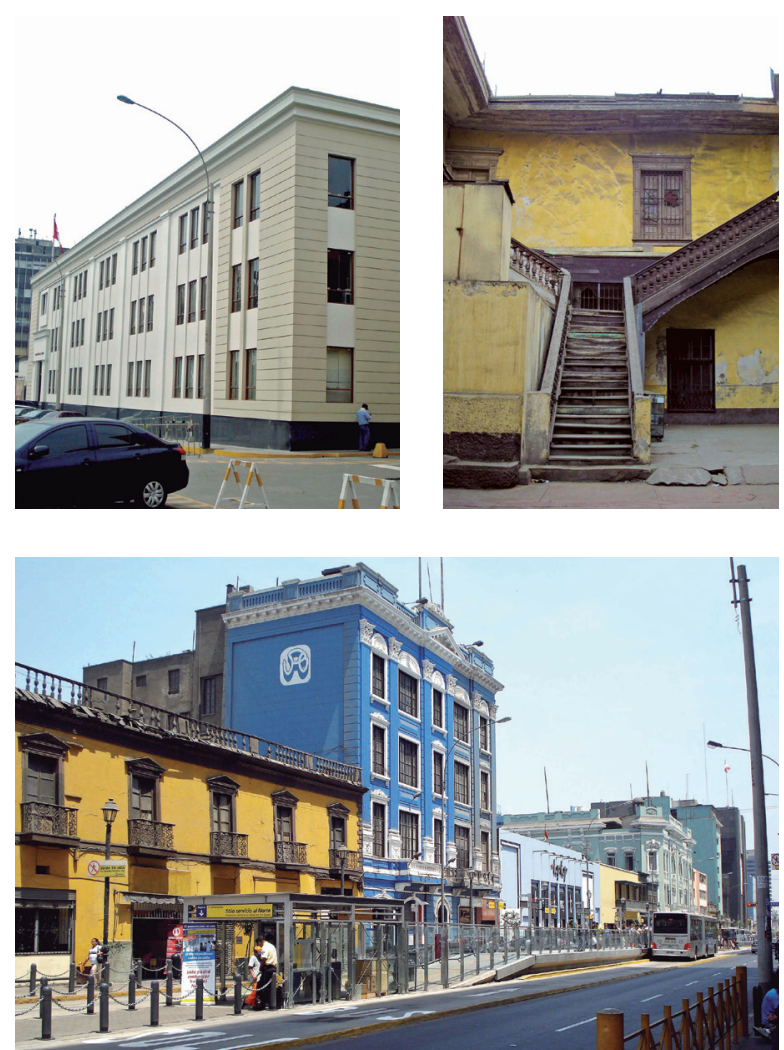

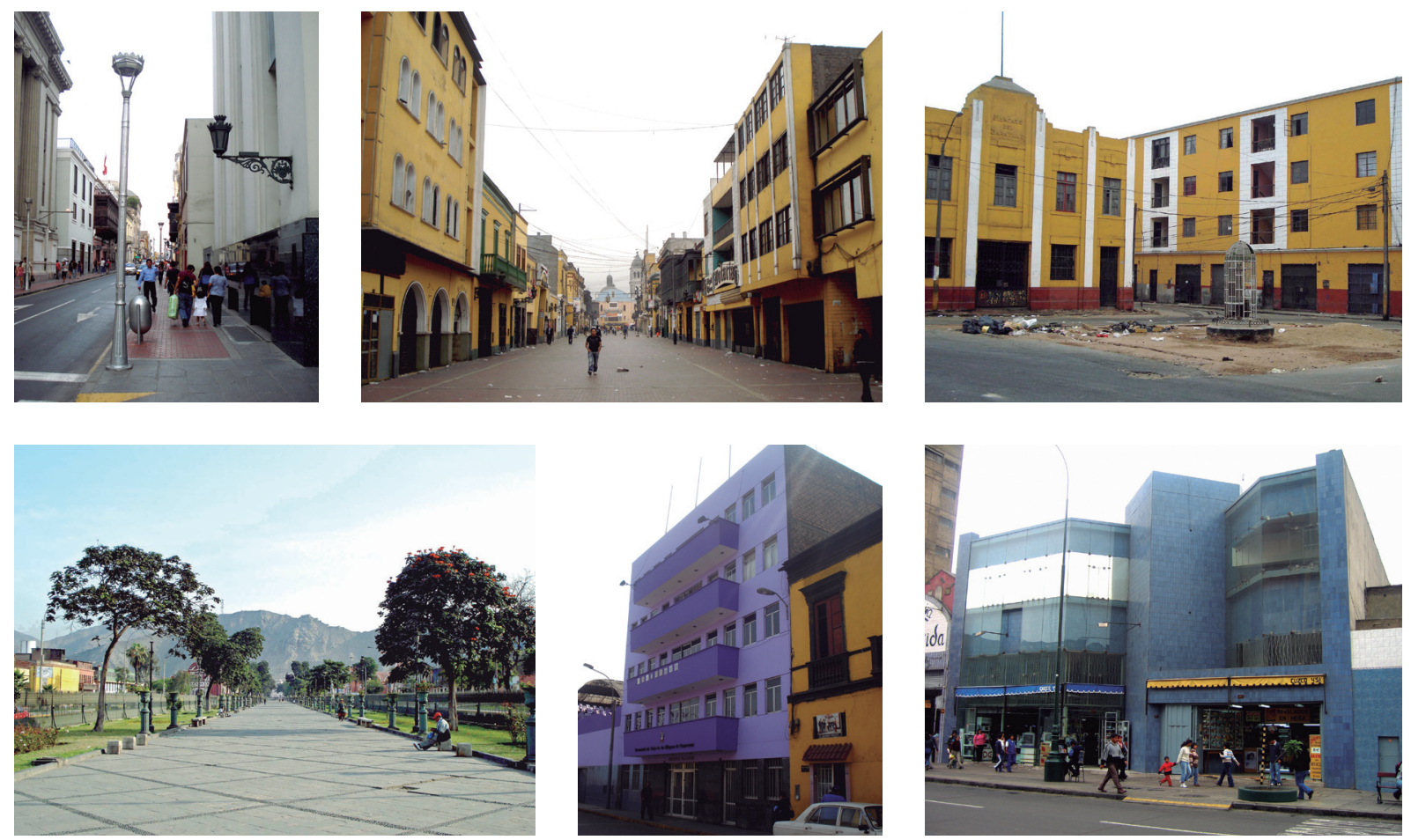

jido urbano y de la visual de importantes monumentos como la Casa Jiménez y la Casa Barragán (Figura 21). Además, advirtió que se había visto alterada la imagen de la ciudad por las nuevas intervenciones en las calzadas y las aceras, cuyos adoquinados en color rojo estaban cambiando el perfil más perdurable para el transeúnte; y por el recién inaugurado mobiliario urbano e iluminación ornamental, instalados como elementos impuestos y discordantes en relación a los existentes y sin considerar el valor del Centro Histórico como unidad integral (Figuras 22 y 23), sumados al estado crítico de deterioro en que se hallaba una gran parte del mobiliario existente. Por ello, se concluye que el valor relacionado con la permanencia de las características de la trama urbana original, que determinaron un patrón en Latinoamérica, se halla amenazado y en peligro, según se detalla más adelante.

Por otro lado, del análisis de los ambientes urbanos en el estudio, se desprendía que sólo el $32.50 \%$ habían tenido intervenciones con impacto positivo. El resto de las intervenciones habían sido negativas, teniendo el $16.05 \%$ impactos menores, el $42.74 \%$ impactos recuperables y el $8.72 \%$ impactos irrecuperables. Los mayores daños correspondían a la pérdida de la Plazuela del Baratillo (Figura 24) y al estado de abandono de la Alameda de los Descalzos con huellas de vandalismo (mutilación de estatuas, grafitis, secciones de rejas faltantes y otros) (Figura 25). Igualmente, determinaba que la integración de la arquitectura contemporánea en el perfil urbano, en general, había afectado los valores urbanos (Figura 26). Eran pocos los ejemplos de buena integración, como los ejecutados en los inmuebles ubicados en el Jr. Lampa 559-561 (en 2002), en el Jr. Azángaro 450 esquina con Jr. Ucayali (en 2009) y en el Jr. Áncash 544 y la calle Simón Rodríguez (en 2008). Por el contrario, predominaban las intervenciones basadas en prototipos de arquitectura moderna sin ninguna intención de integración con el entorno patrimonial (Figura 27), algunos retirados del plomo de la calle $\mathrm{y}$ otros de tipo provisional o precario o de tipo autogestionado, terminados o sin terminar y en uso, mayormente diseñados bajo el concepto de la arquitectura denominada chicha, fortaleciendo una nueva imagen de poco valor estético (Figuras 28 y 29). Es esta nueva configuración de imagen alterna para el Centro Histórico de Lima la que sostiene la degradación de su valor urbano. 
De izquierda a derecha y de arriba a abajo:

Figura 22 (página anterior)

Jr. Ucayali, Lima Cercado.

Figura 23 (página anterior)

Jr. Trujillo, Rímac.

Figura 24 (página anterior)

Plazuela El Baratillo, Rímac.

Figura 25 (página anterior)

Alameda de los Descalzos, Rímac.

Figura 26 (página anterior)

Edificio El Nazareno Jr. Chancay 451-459, Lima Cercado.

Figura 27 (página anterior)

Jr. Cusco 447-451, Lima Cercado.

Figura 28

Jr. Descalzos 133-141, Rímac.

Figura 29

Jr. Descalzos 115-117, Rímac.

Figura 30

Jr. Rufino Torrico 298 esquina con Jr. Callao 400-402, Lima Cercado.

Figura 31

Jr. Huanta 584-586-588-592, Barrios Altos, Lima Cercado.

De igual forma, la aparición de nuevas construcciones edificadas con altura adecuada o con mayor altura sobre pequeños lotes, producto de la subdivisión contemporánea (hoy prohibida), han consolidado un nuevo perfil del Centro Histórico (Figuras 30 y 31). Además, las edificaciones indebidas, erigidas de forma permanente en las azoteas, han elevado la altura de los inmuebles alterando igualmente el entorno urbano (Figura 32). Se trata de un deterioro gradual y deliberado basado en la construcción ilegal (sin licencias y al margen de las normas) que posteriormente se pretender legitimar ante la certeza de que no se ejecutará la demolición de estas obras.

El valor urbano relacionado con la concentración de monumentos de alta calidad cuyos valores individuales se acrecientan al apreciárseles en conjunto, también, se halla afectado. Ello, debido a la constante pérdida de inmuebles considerados menos importantes, pero que son complementarios a los monumentos de primer orden y que al sustraerlos disminuyen el valor urbano al Centro Histórico (Figura 33). Tal es el caso de las dos casonas reconocidas desde la época de la Junta Deliberante Metropolitana de Monumentos Históricos Artísticos y Lugares Arqueológicos de Lima (1962-1963, p. 71) y demolidas
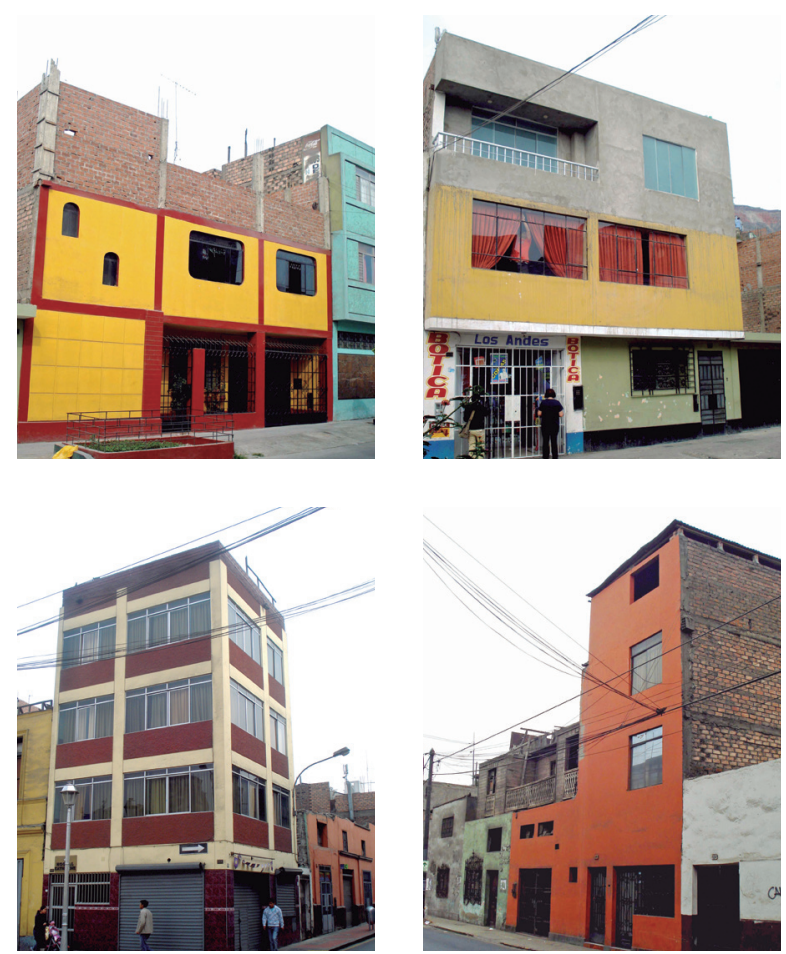

para construir el Centro Comercial El Dorado que se halla en la esquina de los jirones Azángaro y Cusco (Figura 34) y del inmueble demolido en la esquina de la Av. Nicolás de Piérola 1113-1117 con el Jr. Lampa que hoy permanece con una construcción provisional de poca monta.

La pertinencia y compatibilidad de usos ha sido igualmente modificada en casi todo el Centro Histórico (salvo el núcleo fundacional), con la aceptación de usos no compatibles con este, como vivienda-taller o almacén-taller de tipo autogestionado, industria gráfica en inmuebles con pequeños locales para impresión digital no permitidos y/o talleres de imprenta y almacén-depósito. También se advierte que la autorizada ampliación de la antigua fábrica de bebidas gasificadas (instalada en el Rímac desde antes de 1991) (Figura 35) y su anexo (local industrial adecuado en un inmueble de principios del siglo $\mathrm{XX)}$ contribuye a la permanencia del uso industrial. Por ello, el creciente uso industrial de tipo elemental, artesanal y/o de taller gráfico que genera desorden, informalidad y marginalidad, por falta de una acertada acción, es lo que gradualmente ha deteriorado las edificaciones patrimoniales destinadas a tal uso. 

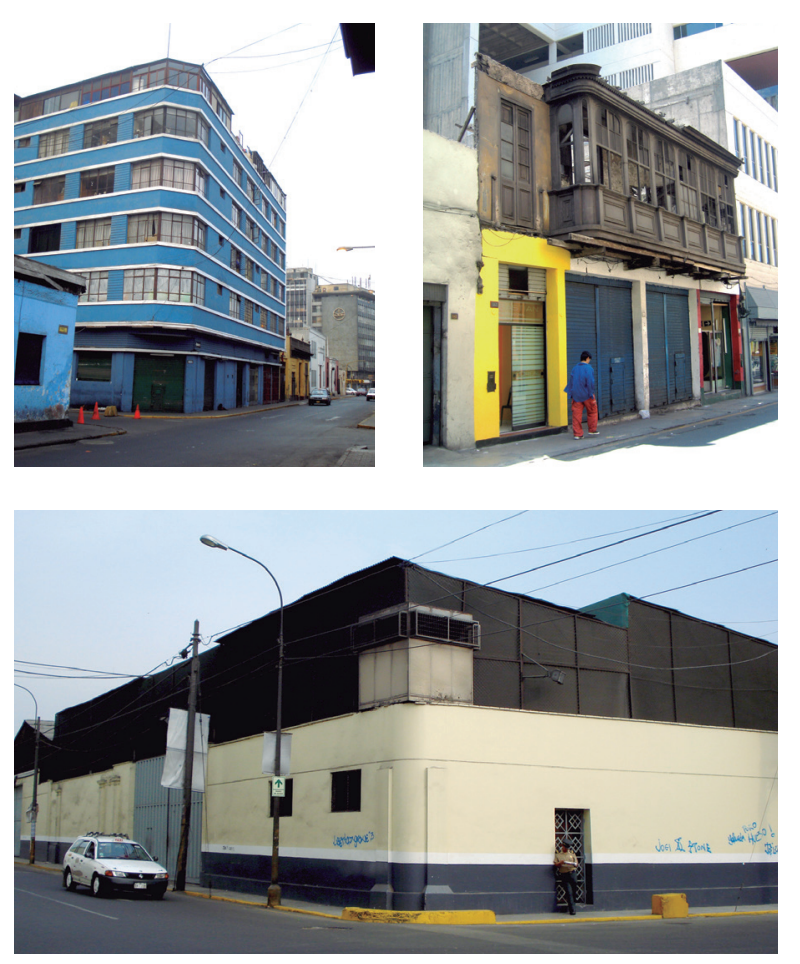

De izquierda a derecha y de arriba a abajo:

Figura 32

Jr. Áncash 582-590-594-598 esquina con Jr. Ayacucho 202206-210-212, Barrios Altos, Lima Cercado.

Figura 33

Jr. Azángaro 557-563-567-573, Lima Cercado.

Figura 34

Centro Comercial El Dorado Jr. Azángaro y Jr. Cusco, Lima Cercado.

Figura 35

Corporación José R. Lindley S.A, Jr. Pataz 252 esquina con Jr. Cajamarca, Barrios Altos, Lima Cercado.

Figura 36

Galería La Movida I, Jr. Cusco 435-443-445, Lima Cercado.
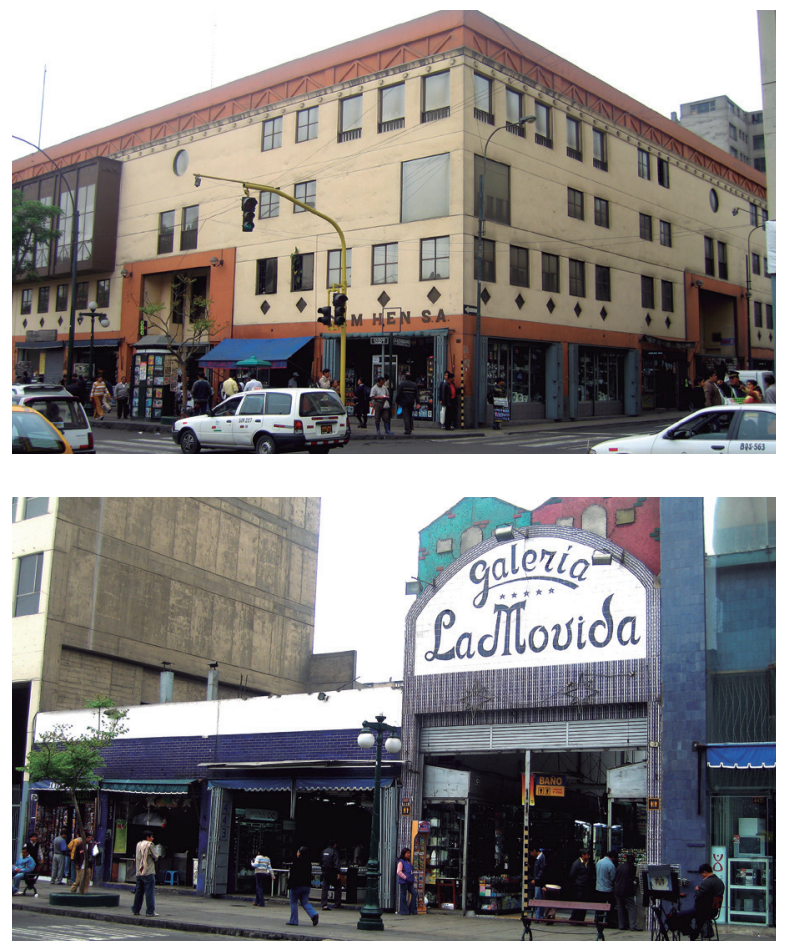

La densificación comercial y el indiscriminado y descontrolado uso y sobreuso del suelo han llevado a la construcción de galerías feriales (Figura 36) y comerciales de varios pisos, mayormente con infraestructura física inadecuada y operando sin licencias de funcionamiento, que han trasformado la configuración de la ciudad. Asimismo, han invadido, subdividido, seccionado y destruido numerosos inmuebles de gran valor patrimonial, convirtiéndose en el nuevo riesgo para la subsistencia del patrimonio edificado. Esta situación que tiene sus inicios en el procedimiento de darle al comercio ambulatorio espacios construidos para que se formalice, ocasionó construcciones antirreglamentarias y carentes de arquitectura pero generadoras de alta plusvalía que se instituyeron como los nuevos espacios informales tolerados por anteriores gestiones municipales. Hoy, mediante el Decreto de Alcaldía № 040 (Municipalidad Metropolitana de Lima, 2001), se ha impedido la construcción de nuevas galerías feriales de habilitación progresiva dentro del Centro Histórico, pero no la edificación de galerías comerciales de formato pequeño ni la instalación de centros y galerías comerciales en inmuebles patrimoniales, quedando estos inmuebles desprotegidos del sobreuso que conlleva esta densificación comercial. Las galerías comercia- 
les que se mantienen operando de forma ilegal y que en los últimos años han proliferado y desvalorizado el Centro Histórico serán formalizadas para permanecer como recordación de las erradas decisiones, de la descontrolada presión inmobiliaria y de la imperfecta normatividad.

Por otro lado, los permisos otorgados entre 2008 y 2010, para desarrollar actividades comerciales en la vía pública, igualmente contribuyen a desvalorizar el ámbito urbano revirtiendo lo recuperado a fines de la década de los noventa. El resurgimiento del comercio ambulatorio que propicia inseguridad, la lotización de la vía pública y el subarriendo de los espacios públicos, al que se pretendió formalizar sin plazo definitivo de desocupación otorgándole un irregular estado legal, es otra prueba de acciones no efectivas. La ineficiencia municipal para hacer cumplir las normas del Centro Histórico, como la Ordenanza Municipal N 062(Municipalidad Metropolitana de Lima, 1994), sumada a la presión social llevaron al caos y la degradación de los valores urbanos. El Anexo 1 del Decreto de Alcaldía Nº 040 (Municipalidad Metropolitana de Lima, 2001) establece la suspensión definitiva del otorgamiento de licencias para imprentas, discotecas y centros de enseñanza (a excepción de academias de ballet y de danzas folclóricas) para evitar la expansión de estos negocios clandestinos, lo que conllevará a la clausura de los locales informales en beneficio de la recuperación del Centro Histórico de Lima. Tanto el desarrollo de la actividad gráfica como el comercio informal deben ser no solo detenidos, sino reubicados en otras zonas compatibles con tales procesos y en forma concertada. Ello, porque despojarlos de la condición legal adquirida puede traer la judicialización del problema.

También se ven afectados los valores arquitectónicos y urbanos por la desocupación de los inmuebles a consecuencia de la insuficiente dinámica del mercado inmobiliario (efecto del deterioro del Centro Histórico) debido al alto costo del mantenimiento de los monumentos y las restricciones que poseen. Pese a ello, se observa la reocupación de algunos edificios representativos adquiridos por parte del sector público, así como la compraventa de edificios emblemáticos por parte del sector privado, donde se advierte la utilización renovada o reciclaje de edificios para oficinas administrativas y locales comerciales y en menor escala para viviendas. Estas positivas intervenciones se dan en el núcleo fundacional y en ciertas zonas puntuales de Barrios Altos y Monserrate y los alrededores de la Plaza San Martin y el Parque Universitario, donde se han incrementado los valores del suelo. No se observa aún una consistente demanda por estos predios dentro del sector privado, siendo todavía moderada la reactivación del mercado inmobiliario del Centro Histórico. Sin embargo, se pronostica que en el futuro se incrementará esta reciente modalidad de inversión revitalizadora, dada la progresiva dinámica inmobiliaria y la concentración de estructuras de calidad, en buen a regular estado, pero con acabados deteriorados e instalaciones obsoletas. Por ello, ante este creciente interés inmobiliario, se advierte que para encontrar un equilibrio que conlleve a la apropiada revalorización del Centro Histórico de Lima se deben regular los límites de la inversión privada y de la intervención de la inversión pública.

El continuo deterioro de las instalaciones de los edificios desocupados ha devenido en una progresiva pérdida del valor inmobiliario, circunstancia desaprovechada dado que la inversión en remodelación, dentro de un centro histórico con lenta recuperación urbana, resulta ser rentable a largo plazo. Esta situación es beneficiosa para aquellas empresas que requieren ubicar sus oficinas en una zona intermedia, más rentable y equidistante entre los distritos sur (como San Isidro y Miraflores) y los distritos norte (de Independencia, Comas y Los Olivos) dado que interactúan con ambas zonas. Igualmente, constituye una buena opción para desarrollar inversiones inmobiliarias exitosas (tanto residenciales como comerciales) que a su vez contribuyan a la recuperación, puesta en valor y sostenibilidad de los inmuebles patrimoniales existentes, hoy en avanzado proceso de deterioro.

A la situación antes descrita se suman los terrenos baldíos (consecuencia principal de casonas demolidas) que a razón de la especulación inmobiliaria que lleva a una gradual presión por la densificación y el cambio de la zonificación, se mantienen como tales o como simples playas de estacionamiento (Figura 37), en espera de obtener mayor utilidad.

Las continuas modificaciones de las alturas, sumadas a las ya ejecutadas a partir del siglo XX, han determinado la transformación de la perspectiva tradicional de las calles y de los ambientes urbanos, perdiendo parte de sus características propias como la continuidad de sus fachadas y la visual abierta que no culminaba en las edificaciones. Esta pérdida de valores urbanos ha llevado a la desintegración de la trama 

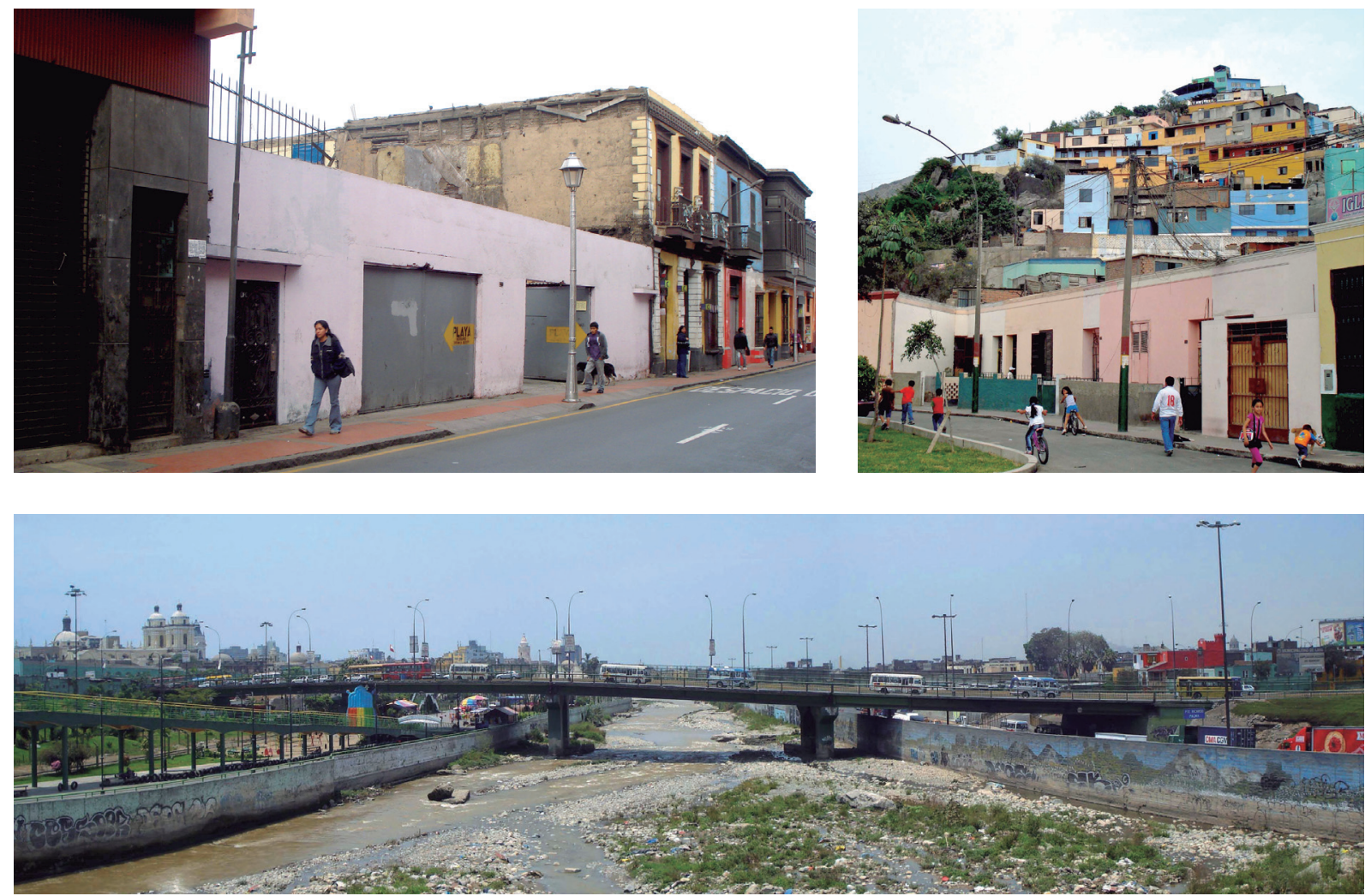

De izquierda a derecha y de arriba a abajo:

Figura 37

Jr. Conde de Superunda sn-423-425, Lima Cercado.

Figura 38

Cerro San Cristóbal desde el Jr. Manco Cápac (Alameda de los Descalzos), Rímac.

Figura 39

Puente Ricardo Palma. y del perfil urbano. Asimismo, las nuevas construcciones mayormente han contribuido a la desvalorización del Centro Histórico de Lima, observándose un desafortunado proceso del incremento del volumen construido con mediocres edificaciones, avaladas por la coyuntura socioeconómica presente y la normatividad vigente.

Igualmente, se halla afectada la vinculación entre el paisaje natural del río Rímac y de los cerros San Cristóbal, El Altillo y Santa Rosa y el paisaje cultural del Centro Histórico por la persistencia de la continua invasión y ocupación de las laderas de los cerros (Figura 38) que refuerza su imagen tugurizada. A ello se suma la disyunción entre el Rímac y Lima Cercado, desarticulados y desarrollándose en forma independiente, creciendo hacia adentro de sus propios núcleos y de espaldas al paisaje del río (Figura 39). Se espera que el Proyecto Vía Parque Rímac, que promueve la actual gestión municipal, revierta este impacto negativo.

Sobre el mismo río, los valores urbanos se hallan amenazados por la presencia del nuevo puente pea- 
tonal Rayos del Sol que ejerce un agresivo impacto visual destacando más que las obras con valor monumental de su entorno.

También han contribuido negativamente, el abandono y el vandalismo existente en los espacios urbanos como la Alameda de los Descalzos; el deterioro progresivo de ambientes urbanos como las alamedas Chabuca Granda y de los Bobos, entre otras; la creación improvisada de nuevos espacios urbanos en áreas edificables, como el "Parque de la Cultura" que generó la ruptura del tejido urbano así como la desvalorización del tradicional Parque Universitario; y la suma de impactos negativos menores como los toldos que forman parte de la imagen perdurable de la Plaza Italia o el pintado en color amarillo de los elementos metálicos del Puente Balta han favorecido a acrecentar la pérdida de los valores urbanos.

A las degradaciones descritas se suma la aparición de veredas pavimentadas en color rojo y con distintas anchuras, que parecieran hubieran sido escogidas al azar o como muestrario, cambiando la percepción del espacio urbano y evidenciando la falta criterio para conservar la unidad. Antes de olvidar la impronta pétrea de la Lima decimonónica, se debió tener en cuenta que, junto a la perspectiva de la calle y al tratamiento de fachadas, el color y la textura del pavimento son el perfil más perdurable para el transeúnte. A esta intervención parcial se le suma la heterogénea nueva iluminación urbana junto con los basureros y bancas instalados en ciertas vías con criterios disimiles y discordantes y sin considerar el valor del Centro Histórico como unidad integral. El actual mobiliario urbano, con elementos perturbadores que por partes bloquean el paso, reafirma la precepción de un ambiente alterado, improvisado, desordenado y sin proyección adecuada.

El Metropolitano, con innegable efecto positivo en el aspecto socioeconómico del transporte público masivo, ha impactado negativamente. A consecuencia de su diseño vial y arquitectónico, se ha generado la inclusión de chimeneas que desvirtúan las proporciones del espacio del Paseo de los Héroes Navales, grietas permanentes en la trama urbana e impactos visuales negativos e irrecuperables que afectan el entorno y los inmuebles; contribuyendo a la desintegración de la trama y a la pérdida de valores urbanos. Este necesario sistema, en tanto rescata la formalidad vial y eleva la calidad de vida de los usuarios, fue ejecutado favoreciendo la renovación urbana y la inversión privada, pero sin considerar la condición patrimonial e histórica de Lima como lo indican las reiteradas recomendaciones de la UNESCO (WHC-11/35. COM/7B, 2011) (WHC-10/34.COM/7B.Add, 2010) (WHC-09/33.COM/20, 2009). Mejorar la accesibilidad, aumentar la población permanente, disminuir el descongestionamiento vial, reducir el ruido y la contaminación ambiental y modernizar la infraestructura urbana eran acciones importantes, tanto como preservar los valores del Centro Histórico, y ninguna debió prevalecer sobre la otra. La bifurcación de la Línea 1, que desde la Estación Central Grau recorre el Jr. Lampa y la Av. Emancipación, era innecesaria y por ello se pudo evitar la quiebra y la destrucción de la trama histórica del área. Se debió proponer rutas alimentadoras o sistema de taxis y/o promocionar rutas peatonales para acceder al núcleo de Centro Histórico en vez de ejecutar 200 metros del paso a desnivel o túnel para el viaducto y los paraderos Colmena, Jr. De la Unión o Carabaya - Camaná y Tacna.

De la misma forma, se advierte que el trazado del tramo 2 del futuro tren eléctrico proyecta la ejecución de una nueva Estación Intermodal Grau (no interconectada con El Metropolitano), así como de estaciones intermedias como las denominadas El Ángel y Martinete, que agrietarán el Centro Histórico de Lima impactando negativamente sobre el Bastión Comandante Espinar de la antigua muralla y sobre el Cementerio Museo Presbítero Maestro. También, se advierte del posible impacto negativo que pudiera ocasionar el del controversial Proyecto del Teleférico de Lima, inicialmente observado por Ministerio de Cultura y reiteradamente señalado por la UNESCO. (WHC-11/35.COM/7B, 2011) (WHC-10/34. COM/7B.Add, 2010) (WHC-09/33.COM/20, 2009). Evitar estos impactos negativos e irreversibles es impostergable y su discusión pública no debe dejarse pendiente para lograr encontrar a tiempo soluciones viables que consideren la preservación de los valores urbanos del Centro Histórico.

Finalmente, se observa que no existe planificación urbano-paisajística con relación a la siembra de árboles y que la incorporación de plantas en las calles y plazas no resuelve los problemas medioambientales existentes, los cuales deben ser solucionados desde su origen: con el control del ruido, del monóxido de los vehículos, del polvo e impurezas en el aire, entre otros.

Con relación a la infraestructura urbana, cabe destacar el éxito del programa de iluminación artística de 
Tabla 1: Lima Cercado y Rímac: Tasas Migratorias, según modalidad migración intrametropolitana de la población de 5 y más años de edad, 2002-2007

\begin{tabular}{lccc}
\hline ÁREA & TASA DE INMIGRACIÓN & TASA DE EMIGRACIÓN & TASA NETA DE INMIGRACIÓN \\
\hline Ciudad de Lima & 13.28 & 13.28 & 0.00 \\
\hline Lima Cercado & 14.90 & 22.12 & -7.22 \\
\hline Rímac & 8.73 & 16.78 & -8.05 \\
\hline
\end{tabular}

Fuente: INEI, Base de datos, micro datos del Censo Nacional de Población y Vivienda del 2007.

Tabla 2: Lima Cercado y Rímac: Tasas Migratorias, según modalidad migración intrametropolitana y del resto del país de la población de 5 y más años de edad, 2002-2007

\begin{tabular}{lccc}
\hline ÁREA & TASA DE INMIGRACIÓN & TASA DE EMIGRACIÓN & TASA NETA DE INMIGRACIÓN \\
\hline Perú & 7.82 & 7.82 & 0.00 \\
\hline Ciudad de Lima & 21.94 & 16.10 & 5.84 \\
\hline Lima Cercado & 24.07 & 35.06 & -10.99 \\
\hline Rímac & 14.92 & 18.86 & -3.94
\end{tabular}

Fuente: INEl, Base de datos, micro datos del Censo Nacional de Población y Vivienda del 2007.

ambientes e inmuebles patrimoniales (Iluminando Nuestra Fe y Hacer Luz), ejecutados por las empresas del Grupo Endesa en el Perú (Edelnor, Edegel, Etevensa y Eepsa) y la Conferencia Episcopal Peruana, a favor de la difusión de la cultura y respetando el bien. Se demostró el éxito de la acción conjunta entre la Iglesia y la participación del sector privado con responsabilidad social. Este programa llevó a que la Municipalidad Metropolitana de Lima contratase a la Arq. Claudia Paz (relacionada con los proyectos de iluminación de Endesa) para la iluminación de la Plaza Mayor, el Palacio Municipal de Lima, el Club de la Unión, los edificios de los Portales, el Edificio Roosevelt, la Plaza San Martín y los edificios de su alrededor. Queda pendiente de ejecución la modernización de las redes de servicio público con la instalación de ductos subterráneos para el tendido de redes sanitarias y de gas, eléctricas, de telefonía y fibra óptica, anulando su impacto visual.

Con respecto al análisis de los valores sociales, el estudio reseña que entre 2002 y 2007, los distritos de Lima Cercado y el Rímac presentaban moderados flujos de inmigración. No obstante, en el intercambio con los distritos perdían migrantes netos, al presentar flujos de emigración mayores (ver Tabla 1). En los últimos años, el Centro Histórico y el Rímac han resultado ser menos atractivos para la migración neta del interior de la ciudad de Lima y se han caracteri- zado por ser expulsores de población (mayormente jóvenes y adultos entre 15 y 64 años de edad) que ha emigrado a otros distritos de Lima en busca de mejoras en la calidad de vida familiar y en las condiciones de estudio o empleo. Ello se refleja en la poca oferta inmobiliaria, privada o subvencionada por el Estado a través de programas como Mivivienda o por programas municipales de renovación urbana y en la escasa presencia de significativos procesos de densificación urbana. Por otro lado, entre 1993 y 2007, la población total de Lima Cercado y del Rímac disminuyó en $56.13 \%$ y la población nacida en Lima decreció en $60.20 \%$ (Instituto Nacional de Estadísticas e Informática, 2007) (ver Tabla 2.) Es decir, la población expulsada era principalmente limeña. Por ello, los valores sociales del Centro Histórico de Lima se hallan en proceso de disminución ante la actual población, mayormente compuesta por inmigrantes y, por ende, con problemas de identificación y permanencia, relegando o degradando los valores sociales originales y generando una ruptura con la tradición precedente.

Los valores sociales también decrecen por la reducción del número de habitantes permanentes que contribuyen a aportar valor vivo al tejido urbano; resultando preocupante el efecto del lento pero continuo proceso de despoblamiento. Asimismo, por la baja calidad de vida que trae como consecuencia el 


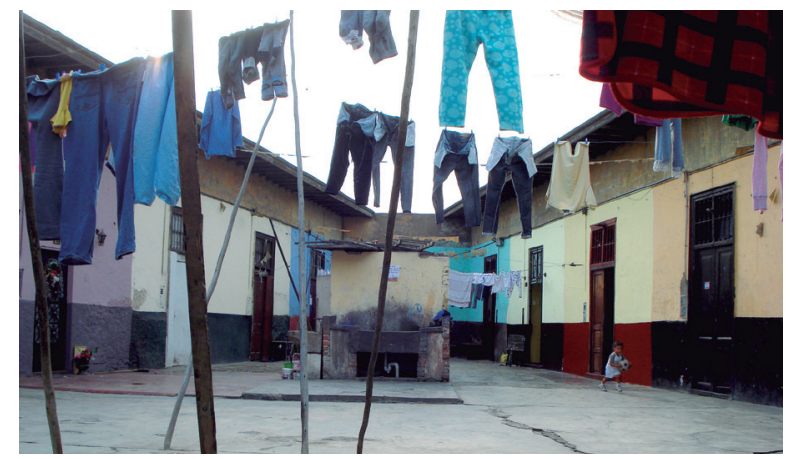

De izquierda a derecha:

Figura 40

Solar Virgen de Fátima, Jr. Hualgayoc 301 a 365 esquina con Jr. García Hurtado de Mendoza 467 a 495, Rímac.

Figura 41

Jr. Cajamarca 450-498 esquina con Jr. Hualgayoc 381-399, Rímac.

crecimiento de la densidad de los tugurios, y por los escasos planes y acciones para la renovación urbana y la inseguridad ciudadana que generan temores e impiden el normal progreso y desarrollo del Centro Histórico.

El problema de los tugurios, estudiado y monitoreado por el Centro de Investigación, Documentación y Asesoría Poblacional - CIDAP, (2009) se hace cada vez más alarmante (Figuras 40 y 41). Entre 1999 y 2004, CIDAP (2004) advertía que en Lima Cercado el número de viviendas hacinadas había aumentado de 23,000 a 27,094 unidades y que la población afectada había pasado de 115,000 a 126,093 habitantes, siendo entre $27 \%$ y $50 \%$ el incremento del número de tugurios y entre $13 \%$ y $24 \%$ el aumento del grado de hacinamiento con relación a 1993, cuando se registraron 18,087 viviendas tugurizadas con 101,688 habitantes. Además señalaba que, en el mismo periodo, las viviendas tugurizadas del Rímac habían crecido de 13,000 a 19,158 unidades y habían pasado a albergar de 67,600 a 103,132 habitantes, cifras muy superiores, tanto en número de tugurios (70\% a $87 \%$ ) como en densidad (171\% a $313 \%)$, a las observadas en 1993, cuando se censarón 6,611 viviendas tugurizadas con 24,962 habitantes. Es decir, en forma constante y progresiva, los tugurios continuaban incrementándose, tanto en número como en grado de hacinamiento (ver Tablas 3 y 4) y afectando prin-

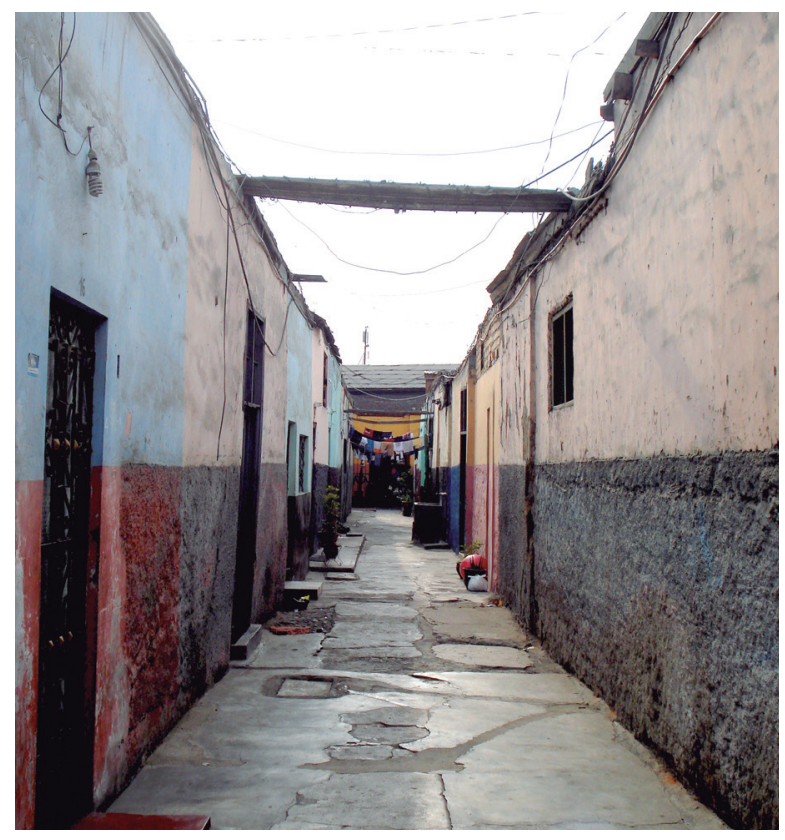

cipalmente a las casonas patrimoniales. Por ello, la población limeña que habitaba en situaciones límite de hacinamiento y de riesgo al colapso de las antiguas casonas ha emprendido lentamente su éxodo del Centro Histórico hacia Lima conurbana.

Los problemas no resueltos de la tugurización y la renovación urbana, por falta de reglas claras y estables e incentivos efectivos que sean atractivos para la inversión privada, siguen contribuyendo a la pérdida de los valores arquitectónicos y urbanos. El último programa de renovación ejecutado por la Municipalidad de Lima demostró ser un éxito relativo por la incapacidad de lograr la recuperar lo invertido para mantener un flujo permanente destinado a la destugurización y la renovación. Por ello, la solución exitosa y efectiva de estos problemas, con inversión pública, privada o mixta, puede alcanzarse mediante una acción conjunta entre el Estado peruano, el Ministerio de la Cultura, la Municipalidad Metropolitana de Lima, la Municipalidad del Rímac, la totalidad de familias que viven en estos inmuebles, el sector privado y las instituciones afines; pero considerando como punto de partida el saneamiento de la titulación y la precarización de la propiedad, el censo de inquilinos precarios y los bonos de destugurización para los pobladores sin acceso a los programas de vivienda económica propia o de renovación, y considerando que el sector privado invertirá solo si existen reglas claras y estables 
Tabla 3: Lima Cercado y Rímac: Evolución del Número de Predios Tugurizados por Año Censal, 1981-2004

\begin{tabular}{lccccc}
\hline CENSO & AÑO & $\begin{array}{c}\text { LIMA CERCADO } \\
\text { Número de predios }\end{array}$ & $\%$ & $\begin{array}{c}\text { RímAC } \\
\text { Número de predios }\end{array}$ & $\%$ \\
\hline INEI & 1981 & 15,660 & 100 & 5,890 & 100 \\
\hline INEI & 1993 & 18,087 & 115 & 5,611 & 95 \\
\hline INEI & 1999 & 23,000 & 147 & 13,000 & 221 \\
\hline CIDAP & 2004 & 27,094 & 173 & 19,158 & 325 \\
\hline
\end{tabular}

Fuente: INEI: Censos de Población y Vivienda, Perú, 1981, 1993, 1999; y CIDAP: Censo de Tugurios, 2004.

Tabla 4: Lima Cercado y Rímac: Evolución Poblacional de los Tugurios por Año Censal, 1981-2004

\begin{tabular}{lcccc}
\hline CENSO & AÑO & $\begin{array}{c}\text { LIMA CERCADO } \\
\text { Número de predios }\end{array}$ & $\%$ & $\begin{array}{c}\text { RÍMAC } \\
\text { Número de predios }\end{array}$ \\
\hline INEI & 1981 & 67,571 & 100 & 25,486 \\
\hline INEI & 1993 & 101,688 & 115 & 24,962 \\
\hline INEI & 1999 & 115,000 & 147 & 67,600 \\
\hline CIDAP & 2004 & 126,093 & 173 & 103,132 \\
\hline
\end{tabular}

Fuente: INEI: Censos de Población y Vivienda, Perú, 1981, 1993, 1999; y CIDAP: Censo de Tugurios, 2004.

e incentivos efectivos o exoneraciones, los cuales a futuro serán beneficiosos para la comunidad. Ello, porque nadie (salvo que sea una entidad de beneficencia) arriesga sus recursos en un proyecto no rentable.

Entre los mayores obstáculos existentes para la inversión privada debe incluirse, además, la inseguridad ciudadana, la limpieza pública y contaminación, el tránsito vehicular y el desorden, y los largos plazos que toman las aprobaciones de los proyectos y las gestiones entre la Municipalidad Metropolitana de Lima y el Ministerio de la Cultura, que pueden prolongarse durante varios meses, así como en los trámites con el INDECI. De todos estos, el que mayor daño causa es el elevado índice de inseguridad ciudadana que aún persiste en el Centro Histórico, y el alto grado de peligrosidad urbana en Barrios Altos y en el Rímac, donde los servicios de seguridad ciudadana no proporcionan la cobertura requerida por limitaciones presupuestales, por la desmoralización y corrupción de las instituciones, y por la exclusión o subestimación de la responsabilidad de los alcaldes. Esta situación se agrava por la percepción negativa de los ciudadanos acerca de los policías y los serenos y la consecuente pérdida de la confiabilidad. Para mejorar los niveles de seguridad principalmente se requiere integrar a la Policía Nacional, a las autoridades municipales y sus servicios de Serenazgo, a los bomberos, a Defensa Civil, a los medios de comunicación y los ciudadanos comunes a través de las juntas vecinales; tener una fuerza policial y de serenos honrada, fuerte, capacitada y confiable; modernizar la infraestructura; y difundir políticas orientadas a la prevención del consumo de drogas, del abuso del alcohol, de los delitos contra el patrimonio, de la vida, del cuerpo y de la salud, males que aún persisten en el Centro Histórico.

Dentro de la actual población existe, por otra parte, un elevado índice de frustración social que se refleja en el aumento de la delincuencia, la mendicidad, el tráfico de tóxicos, el pandillaje, el proxenetismo y la prostitución clandestina, sumados a la corrupción en las entidades públicas y el Poder Judicial, las restricciones de acceso a la propiedad y el mercado, y las trabas administrativas. A pesar de los esfuerzos por incrementar el nivel de la seguridad ciudadana, en 2010 la percepción de seguridad en Lima Cercado alcanzó el 58.2\% (291/500 puntos) y en el Rímac llegó a 49.6\% (248/500 puntos); siendo el Rímac el distrito con menor precepción de seguridad de Lima Metropolitana (Costa \& Romero, 2010, p. 39). Consecuentemente, la percepción de inseguridad en Lima Cercado era del $41.8 \%$ y en el Rímac del 50.4\%. Resultaba muy superior a los indicadores registrados en 1993, cuando la percepción de inseguridad en Lima Cercado era de $29.3 \%$ y en el Rímac era de $5.4 \%$ (del 
Mastro V \& Sánchez León, 1993) y en 2004 cuando en el Cercado de Lima era de $28.9 \%$ y en el Rímac era de $11.4 \%$. (Bernex, 2004, p. 175).

Las políticas de mantenimiento y conservación del Centro Histórico de Lima deberían considerar tanto la integridad física urbana como la identidad y el organismo social activo existente en ella, solucionando los problemas que causan su deterioro y evitan su revitalización, y favoreciendo a la población existente con mejor nivel de vida e interesando a la población fluctuante, especialmente los que trabajan allí, a querer residir en el Centro Histórico.

Del estudio de los valores culturales de Lima se deduce que los principales resultan ser las festividades religiosas, las corridas de toros, el criollismo popular, la cultura chicha y la gastronomía. Las corridas de toros y las festividades religiosas limeñas, especialmente la procesión del Señor de los Milagros, son los valores culturales más antiguos y los que menos variaciones han tenido en el tiempo. Hasta hoy permanecen casi intactos con toda su parafernalia, llevándose a cabo con gran devoción y difusión. A estas se les ha sumado las festividades provincianas, como el Señor de Muruhuay y la Virgen de Chapi que han enriquecido esta identidad cultural.

Por otro lado, el valor cultural de la gastronomía limeña no solo permanece sino que se ha acrecentado debido a la constante difusión que tiene la gastronomía peruana. Esta identidad es la mejor promovida y explotada comercialmente y su difusión tiene trascendencia internacional, al tratarse no solo de una consistente identidad sino un medio de intercambio con otras culturas. Conservadora pero no estática, la gastronomía limeña ha sido sensible a la fusión y mestizaje: las mutaciones, la imitación y los préstamos. Así esta ha llegado al presente con influencias de las cocinas española, árabe, africana, italiana, japonesa, china y andina, que la han diversificado culturalmente. Actualmente, en el Centro Histórico se desarrollan festivales culinarios como los que se realizan semanalmente en la Plaza Italia y ocasionalmente en el Barrio Chino y en los Parques Chabuca Granda y de la Reserva, donde en una ocasión se efectuó el Festival Gastronómico de Mistura.

Contrariamente a las festividades y a la gastronomía, el criollismo popular que se identificaba plenamente con lo limeño en Barrios Altos, Monserrate y el Rímac, hoy se encuentra en proceso de desvalorización por el creciente desinterés por promoverlo y difundirlo, favoreciendo la pérdida de su efectividad como valor cultural. El criollismo popular resulta ser una forma de integración, donde la galantería, la picardía y la diversión exhibicionista (relacionadas la cultura afroperuana y la picardía española) sobresalen como medio de subsistencia. Es “...un código cultural de interacción social que incorpora selectivamente como iguales a todos aquellos que conocen sus prácticas de identificación ritual, sin hacer distingos étnicos o de clase", pero prescindiendo del aporte indígena y de "...quienes no conocen o ignoran sus códigos de interacción...” (Panfichi H. \& y Portocarrero S., 2004, p. 39). Este código tiene sus orígenes en el virreinato, al lograrse la mixtura de la hidalguía española y la solidaridad entre iguales con lo festivo de las reuniones de las clases bajas, antecesoras de las jaranas y esencia de la identidad criolla popular. Hoy, los pocos centros musicales (Figura 42) que todavía lo difunden, manteniendo viva la canción criolla, no cuentan con el apoyo de las autoridades municipales.

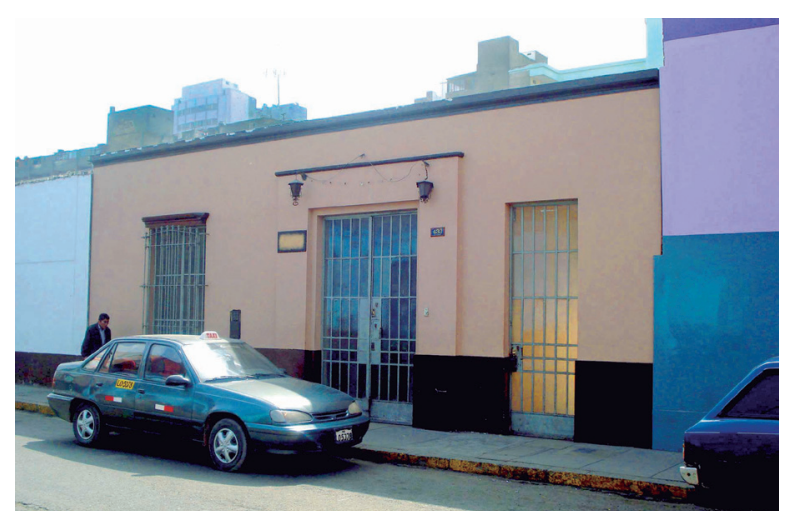


Igualmente, el lento pero continuo proceso de despoblamiento y el incremento de la migración provinciana contribuyen al reemplazo del criollismo por la nueva cultura chicha en la dinámica de la cultura viva del Centro Histórico de Lima. Por ello, se halla en peligro la permanencia del criollismo como hecho cultural y se reconoce a la cultura chicha como el nuevo valor cultural de Lima.

La consolidación de la cultura chicha se desarrolla y afirma a partir de las transformaciones de la sociedad limeña, ante el proceso histórico de las migraciones y los cambios que ocurrían en su entorno, como la aparición desmesurada del comercio informal, las combis y las invasiones de los cerros, entre otros. Ello llevó a la mutación de la cultura urbana, donde el criollismo dejaba de ser efectivo y donde emergían cambios que eran rápidamente asimilados, dando paso a la nueva figura social que aportaba con efectividad en la dinámica de la cultura viva limeña, ganando progresivamente su reconocimiento. Dentro de la arquitectura se le reconoce como estilo chicha, dentro del lenguaje popular como nueva jerga o jerga chicha y prensa chicha o sensacionalista, en lo espiritual en la religiosidad sin dogma, en la moda con marcas copiadas o alternas, en la música chicha con la tecnocumbia y el tecnorock, en la discografía con las ediciones pirata y en de las artes con la iconografía chicha de gráficos fluorescentes multicolores que son, hoy, los "afiches de neón" promovidos y reconocidos en países vecinos como Chile. Igualmente, ha adquirido mayor difusión la medicina alternativa que reemplaza o complementa la medicina tradicional y donde los chamanes andinos tienen mayor popularidad. Por todo ello, se reconoce a la cultura chicha como el nuevo valor cultural de Lima.

El análisis de los valores históricos de Lima lleva a concluir que estos se preservan como una confluencia de eventos donde resalta el reconocimiento de la ciudad de Lima como patrón de las ciudades españolas en América Latina y capital del Imperio Español en América del Sur durante el virreinato, protagonizando acontecimientos históricos que determinaron la concentración de poder y la riqueza. Asimismo, se reconoce que su jerarquía y desarrollo se debieron al centralismo político, económico y administrativo, que sus transformaciones se deben en lo físico a las reconstrucciones y cambios exigidos por frecuentes terremotos y, en lo ideológico, a la influencia del afán de modernidad y progreso de sus nuevos intelectuales, y que sus perturbaciones se atribuyen a la crisis económica, a la masiva migración provinciana $y$ al registro de hechos que perduran en la memoria limeña, como los estragos del terrorismo y la matanza de Barrios Altos.

La afirmación de los referentes históricos está a cargo de las instituciones culturales y de la Municipalidad Metropolitana de Lima, quienes los promocionan y difunden, principalmente, durante las celebraciones de la fundación de la ciudad de Lima, de la Semana Santa y del Día Internacional de los Museos, cuando se programan circuitos peatonales para recorrer y conocer el Centro Histórico de Lima y sus museos. No obstante, hasta finales de 2010, se observaba la inexistencia de un museo de la historia de la ciudad de Lima. Dicho museo fue recién inaugurado el 9 de octubre de ese año, bajo el nombre de Museo Metropolitano de Lima, en el antiguo edificio del Ministerio de Transporte y Comunicaciones que fue restaurado y reciclado para tal fin.

Actualmente, la opinión pública asocia lo políticamente correcto con el enaltecimiento del legado prehispánico y el desinterés por la herencia virreinal. Por ello, la falta de afirmación del hecho cultural de la fusión del espíritu indígena con las corrientes europeas ha provocado que la dinámica de la continuidad de la tradición se halle perturbada y su identidad transformada, y esto ha llevado al consentimiento de los daños causados al Centro Histórico de Lima y al reemplazo de este valor cultural por la nueva cultura chicha en la dinámica de la cultura viva. Igualmente, la falta de la afirmación de la referencia histórica, su poca promoción y difusión han contribuido a la pérdida de valores urbanos, tal es el caso de la antigua Plaza Pizarro (hoy Plaza Perú), de las mutilaciones de las estatuas y placas conmemorativas, entre otros, que demuestran la poca conciencia urbana con relación a las obras de arte público y los espacios urbanos. También han contribuido a la desfiguración de los espacios urbanos, siendo el Parque Universitario (por la presencia del Parque de la Cultura) una prueba de ello. "Esta intervención negativa ha traído como consecuencia un nuevo rostro para el ambiente urbano, donde se observa la pérdida de la perspectiva visual del tradicional espacio monumental, la ruptura del equilibrio y la proporción existente entre el Parque Universitario y los edificios que lo contenían, la liberación de fachadas de poco valor (a excepción de la Iglesia de los Huérfanos) que evidencian el deterioro de la imagen urbana del Centro Histórico y la presencia en primer plano del antiguo Ministerio de 
Educación que con sus modernos veintiún pisos se impone sobre monumentos de poca altura pertenecientes a los siglos XVIII y XIX, como la Casona de San Marcos, la Supresa de San Carlos, la Iglesia de los Huérfanos, entre otros" (Rodríguez Larraín E., 2012, pp. 100-101). Los espacios respetados y apreciados no se deprecian por el vandalismo; por ello, la identidad cultural limeña y su pasado histórico deben ser promovidos y explotados para que contribuyan a la protección del propio Centro Histórico.

Se observa la poca continuidad de las obras correspondientes a las distintas alcaldías, evidenciándose que por intereses políticos los alcaldes han tendido a abandonar los proyectos fomentados por sus antecesores. Asimismo, que por iniciativas demagógicas se han destruido espacios tradicionales (Plaza Pizarro, entre otros) o han desfigurado estos (Parque Universitario por la presencia de la Plaza de la Cultura), no existiendo conciencia urbana con relación a las obras de arte público y los espacios urbanos. También la poca exposición al público de los proyectos que afectan a la ciudad y la desvinculación entre la pretensión municipal y la opinión de expertos (como la UNESCO, Ministerio de la Cultura y otros) y el público en general. Igualmente, se ha evidenciado la defectuosa y casi nula influencia que la opinión de estos expertos ejerce cuando se califica las decisiones municipales que resultan erradas, evadiendo la enorme responsabilidad que les compete en cuestiones de protección del Centro Histórico bajo la limitación de ser únicamente entes reguladores, siendo el caso más lamentable el de la aprobación de la construcción de la Estación Jr. De la Unión. Todo ello determina gestiones municipales parcialmente inadecuadas y una protección legal imperfecta, que son contrarias a lo requerido para la inclusión de un centro histórico en la Lista del Patrimonio Mundial. No basta con tener un valor excepcional universal y autenticidad, hay que tener también una protección legal y una gestión adecuada, donde se analicen los impactos de los proyectos en forma integral y no en procesos independientes que son producto de la improvisación o de la imposición del afán político.

Por otra parte, dentro de las principales causas de la pérdida de una porción importante de los inmuebles patrimoniales y de la disminución de los valores arquitectónicos de los que aún se conservan, que afectan la autenticidad del Centro Histórico, se encuentran la poca efectividad en la aplicación del marco legal para la protección y recuperación de los valores urbanos y la inexistencia de planes integrales de restauración, preservación y renovación urbana y de un diagnóstico actualizado de los bienes patrimoniales. Además de la falta de una visión integral del desarrollo de la ciudad, también ha contribuido la limitada noción sobre el valor del patrimonio urbano y arquitectónico de Lima que tienen las autoridades edilicias y lo poco difundido entre los ciudadanos comunes, pero usuarios directos de la ciudad.

Igualmente, la lentitud en la reglamentación e implementación de las normas dictadas ha sido un factor que ha incidido en los impactos negativos producidos. Tal es el caso del Decreto Legislativo $\mathrm{N}^{\circ} 696$ (Congreso de la República del Perú, 1991) Ley de Promoción a la Inversión Privada en acciones de Renovación Urbana, reglamentado mediante el Decreto Supremo No 11-95-MTC (Ministerio de Transportes y Comuniaciones, Vivienda y Construcción; Ministro de la Presidencia, 1995) e implementado por la $\mathrm{Mu}-$ nicipalidad Metropolitana de Lima en el 2003 (Decreto de Alcaldía $N^{\circ} 161,2003$ ) (Decreto de Alcaldía $\mathrm{N}^{\circ}$ 162, 2003) (Decreto de Alcaldía $\mathrm{N}^{\circ} 177,2003$ ). Doce años después de su dación se puede recién iniciar de forma efectiva la recuperación y la protección del Centro Histórico de Lima y la prevención y el control de su deterioro urbano. Igualmente, la sectorización de Lima efectuada por la Municipalidad Metropolitana de Lima en 1997, fue priorizada y normada a través del Plan Maestro del Centro Histórico y Cercado de Lima (Municipalidad Metropolitana de Lima, 1998) Estas dos normas complementarias aún no han sido revisadas ni compatibilizadas a favor del Patrimonio Monumental e Histórico. Otras normas declaradas inaplicables, como el Decreto de Alcaldía No 060 (Municipalidad Metropolitana de Lima, 2003), que para proteger al Centro Histórico de Lima lo declaró zona rígida para cualquier tipo de concentración pública, marchas y manifestaciones, violando el derecho de reunión en la vía pública. Las consecuencias no solo fueron la derogatoria de esta norma, sino la inaplicabilidad del inciso f del Artículo 132 de la Ordenanza Municipal No $062^{2}$ (Municipalidad Metropolitana de Lima, 1994) que esta regula.

Incide en este aspecto, según se ha citado, la poca efectividad de las normas que protegen a los monumentos, algunas con deficiencias que impiden su correcta aplicación, y los lentos procesos de investi-

2. Marco normativo para la declaratoria del Centro Histórico de Lima como Patrimonio Cultural de la Humanidad. 
gación de la violación de las normas. Tal es el caso de la casona antes ubicada en el Jr. Azángaro 556, que a pesar de estar protegida mediante la $\mathrm{RM} \mathrm{N}^{\circ} 928-80$ ED (Ministerio de Educación, 1980) y la RS N 2900 72-ED (Ministerio de Educación, 1972) fue demolida (junto con la casona vecina para edificar la Galería El Dorado). Asimismo, la reciente restauración con adecuación a galería comercial de la casona ubicada en el Jr. Huallaga 458-460-462-466 fue ejecutada de forma incorrecta y desvirtuando su conformación interior. Según los archivos del antes INC, en ambos casos se aplicó la correspondiente multa y se abrió proceso de investigación por el retiro de la condición de monumento (Ministerio de la Cultura, 2007). La insuficiencia en la protección del Centro Histórico por parte del hoy Ministerio de la Cultura, sea por falta de recursos económicos, por la deficiencia de las normas o por limitaciones en la gestión, lo hacen también responsable por la pérdida de innumerables inmuebles patrimoniales y por el deterioro alcanzado por los impactos negativos descritos. Asimismo, devela que las prerrogativas técnicas del Ministerio de la Cultura lo limitan legalmente y son insuficientes para una real protección, conservación y restauración de los bienes patrimoniales, que requieren de una voluntad política que no es prioritaria para el Estado ni para la Municipalidad Metropolitana de Lima, aun cuando tienen la obligación de defender, aportar, apoyar y asesorar en materia de conservación y restauración del patrimonio.

Poco efectivas han sido también las últimas reformas administrativas municipales establecidas durante la anterior gestión, que generaron nuevos entes complementarios a los existentes, que además eran dirigidos por la misma persona, como sucedió en el Programa de Administración del Centro Histórico de Lima - PROLIMA (entidad planificadora) y en la Empresa Municipal Inmobiliaria de Lima SA - EMILIMA (entidad ejecutora). Ambos deberían estar integrados para facilitar las acciones de gestión y de administración del Centro Histórico. Asimismo, la creación de la nueva Comisión Técnica Especial Calificadora de Proyectos del Centro Histórico y Cercado de Lima en reemplazo la Comisión Técnica Especial Calificadora de Licencias de Construcción para el Centro Histórico y el Cercado de Lima, que trae como consecuencia el incremento del número de los representantes vinculados al municipio. La nueva conformación, con un desequilibrado peso entre sus representantes, ha dado como resultado que los proyectos que afectan al Centro Histórico pueden ser aprobados por razón de los votos de los miembros vinculados al municipio, dependientes de una misma autoridad, prescindiendo del consentimiento de los miembros profesionales especialistas en conservación (con derecho a opinión).

Finalmente, hay intervenciones negativas por la incultura y la falta de responsabilidad ciudadana, como las construcciones ilegales recientes efectuadas de forma permanente y alterando gradualmente el perfil urbano; el pintado de edificios por secciones, delimitando las distintas propiedades o posesiones, en vez de ser pintados de manera integral para toda la unidad; la utilización de colores estridentes o discordantes o la colocación de materiales vidriados como gres, cerámicas o azulejos en las fachadas por ser extraños para el Centro Histórico; la colocación de avisos publicitarios o carteles que se encuentran de forma clandestina y que, además, afectan visualmente a los monumentos, o que se hallan en fachadas laterales o posteriores, azoteas o muros de terrenos sin construir, postes de alumbrado y otros que igualmente afectan las aceras y los ambientes urbanos. En general, los avisos publicitarios que se autoricen deberían armonizar en forma, textura y colores con las características del Centro Histórico.

La relación entre la subsistencia de los argumentos que fundamentaron la declaración de Patrimonio Cultural de la Humanidad al núcleo del Centro Histórico de Lima y la autenticidad del Centro Histórico, nos lleva a concluir que innegablemente el Centro Histórico de Lima sigue siendo "un área urbana fuertemente condicionada por una estructura física proveniente de la época virreinal, reconocible como el patrón arquitectónico-urbanístico de las ciudades virreinales de América Latina y representativa de la evolución de la arquitectura de reinterpretación y de creación local, que testifica la identidad y verdad de la Ciudad de Lima" (Ministerio de la Cultura, 19901991). No obstante, se advierte que la disminución de sus valores y autenticidad son efectos continuos de intervenciones anteriores y recientes que, ocasionadas por erradas decisiones municipales, toleradas por instituciones ineficientes que no logran ejercer protección y apoyadas en marcos legales defectuosos o aplicados en partes, lo están llevando en forma acelerada a su desvalorización y a la pérdida de su condición como Patrimonio Cultural de la Humanidad. No se ha asumido el íntegro de la responsabilidad que tal nominación requería. Lima y su Centro Histórico han continuado evolucionando y desarrollán- 
dose bajo lineamientos generales, sin una efectiva planificación urbana que estuviera realmente basada en los criterios para la conservación del patrimonio establecidos en la Convención del Patrimonio Mundial de UNESCO. La desintegración parcial de la trama y del perfil urbano, la disminución de los edificios históricos y de los valores intrínsecos en algunos monumentos, la disminución del alto nivel expresivo de la técnica de construcción en adobe reforzado con ladrillo y piedra, la falta de reconocimiento del hecho cultural de la fusión del espíritu indígena con las corrientes europeas, la permanencia y disminución de calidad de vida de la población, y la falta de la afirmación de la referencia histórica, su promoción y difusión, han puesto en peligro la subsistencia de los argumentos que fundamentaron la declaración de Patrimonio Cultural de la Humanidad. Ello, porque se han abordado los problemas inmediatos o los más agobiantes, en procesos discontinuos y sin registrar ni sistematizar las intervenciones urbanísticas o sin monitorear los indicadores de los factores de riesgo patrimonial.

La preservación y el mantenimiento del Centro Histórico de Lima están relacionados a una compleja problemática, cuyos aspectos normativos, socioculturales, económicos y de seguridad ciudadana constituyen las principales dificultades para resolver la crisis urbana; donde la destugurización, la seguridad ciudadana integrada, la inversión inmobiliaria, la expropiación de inmuebles patrimoniales en peligro de perderse, la reintegración de las fragmentaciones del tejido urbano, la preservación de la escala, la reutilización de edificios obsoletos y la consolidación de los terrenos baldíos se hacen imperativos para lograr la

\section{Bibliografía}

Bernex, N. (2004). Inseguridad y Miedos en Lima: Realidad y Percepción de Nuevas Arquitecturas Espaciales. En O. Gutiérrez (coord.) La Ciudad y el Miedo. Girona, Cataluña, España: Universitat de Girona.

Centro de Investigación, Documentación y Asesoría Poblacional . (2004). Censo de Tugurios. Lima: CIDAP.

Centro de Investigación, Documentación y Asesoría Poblacional. (2009). 474 Aniversario de Lima, Acciones de Renovación Urbana para hacer de Lima un Centro Vivo. Lima: CIDAP. recuperación urbana. Hace veintidós años que permanentemente se indica que su continuo proceso de deterioro podría llevar a la irrecuperable pérdida de un maravilloso y único centro histórico que constituye nuestra memoria colectiva. Asimismo, que es impostergable la reformulación de las acciones de intervención, a fin de lograr la adecuada revalorización del área como parte de la responsabilidad adquirida. Hoy, estas advertencias se amplían al hacerse prioritario exponer al público los grandes proyectos que afectan la ciudad, así como el establecer el equilibrio entre los límites de la inversión privada y la intervención de la inversión pública para evitar la depreciación futura de los valores y significados que aún permanecen.

Las conclusiones expuestas, producto de la investigación del estado actual de los valores urbanos, arquitectónicos, sociales, culturales e históricos del tejido urbano y de las áreas construidas o construibles, demuestran que la situación actual no permite acreditar resultados positivos en la conservación del área tras su declaración como Patrimonio de la Humanidad.

De ello, se desprende la necesidad de ejecutar un monitoreo más profundo del Centro Histórico, de inventariar los historiales urbanísticos de los procesos de intervención realizados sobre su tejido urbano, de efectuar un proceso permanente y coordinado de acciones preventivas y correctivas para evitar el mayor deterioro físico de la trama original, los inmuebles y ambientes urbanos, de reforzar la imagen que los limeños tienen de su espacio nuclear fundacional y de hacer la revisión integral y compatibilización del marco legal que lo regula para rescatarlo en forma efectiva y sostenible.
Congreso de la República del Perú. (noviembre de 5 de 1991). Decreto Legislativo № 696. Ley de Promoción a la Inversión Privada en Acciones de Renovación Urbana. Lima, Perú.

Congreso de la República del Perú. (25 de mayo de 2003). Ley N²7972. Ley Orgánica de Municipalidades. Lima, Perú.

Congreso de la República del Perú. (2 de julio de 2004). Ley № 28296. Ley General del Patrimonio Cultural de la Nación. Lima, Perú. 
Costa, G., Romero, C. (2010). Inseguridad Ciudadana en Lima ¿Qué Hacer? Lima: Ciudad Nuestra.

del Mastro V, M., Sánchez León, A. (1993). En el Juego de la Vida. Ser Delincuente en Lima. Lima, Perú: DESCO, Centro de Estudios y Promoción del Desarrollo.

Instituto Andaluz de Patrimonio Histórico (compilador) (1999). Cuadernos Indicadores para la Evaluación del Estado de Conservación de iudades Históricas. (C. d. Junta de Andalucía, Ed.) Granada, Andalucía: Comares.

Instituto Nacional de Estadísticas e Informática (2007).XI Censo Nacional de Población y VI de Vivienda. Lima: INEI.

Junta Deliberante Metropolitana de Monumentos Históricos, Artísticos y Lugares Arqueológicos de Lima (1962-1963). Informe de la Comisión Calificadora de los Monumentos Coloniales y Republicanos (Vol. Número 6). Lima, Perú: MML.

Ministerio de Educación (28 de diciembre de 1972). Resolución Suprema º 2900-72-ED. Lima, Perú.

Ministerio de Educación (23 de julio de 1980). Resolución Ministerial N 928-80-ED. Lima, Perú.

Ministerio de la Cultura (1990-1991). Expediente de Nominación del Centro Histórico de Lima. Lima: INC, Municipio de Lima Metropolitana, Patronato de Lima y UNESCO.

Ministerio de la Cultura (2007). Registro de Bienes Culturales Inmuebles que Cuentan con Retiro de Condición. Lima, Perú.

Ministerio de Transportes y Comunicaciones, Vivienda y Construcción; Ministro de la Presidencia (24 de julio de 1995). Decreto Supremo No 11-95-MTC. Reglamento de la Ley de Promoción a la Inversión Privada en Acciones de Renovación Urbana. Lima, Perú.

Municipalidad Metropolitana de Lima (18 de agosto de 1994). Odenanza Municiapal $N^{\circ} 062$. Reglamento de Administración del Centro Histórico de Lima. Lima, Perú.

Municipalidad Metropolitana de Lima (21 de diciembre de 1998). Ordenanza Municipal № 201. Plan Maestro Centro de Lima. Lima, Perú.

Municipalidad Metropolitana de Lima (24 de abril de 2001). Decreto de Alcaldía Nº40. Reglamento de Centros y Galerías Comerciales en el Centro Histórico y del Cercado de Lima y de las Galerías Feriales Incluidas las de Habilitación Progresiva en el Cercado de Lima. Lima, Perú.

Municipalidad Metropolitana de Lima (19 de setiembre de 2003). Decreto de Alcaldía $N^{\circ} 162$. Identifican Microzona de Tratamiento de Renovación Urbana. Lima, Lima, Perú.

Municipalidad Metropolitana de Lima (18 de setiembre de 2003). Decreto de Alcaldía $N^{\circ} 161$. Identifica- ción de Tratamiento de Renovación Urbana en el Centro Histórico de Lima. Lima, Perú.

Municipalidad Metropolitana de Lima (11 de noviembre de 2003). Decreto de Alcaldía № 177. Lima, Perú.

Municipalidad Metropolitana de Lima (20 de enero de 2003). Decreto de Alcaldía № 060. Declaran como zona rígida para cualquier tipo de concentración pública, al sector del Centro Histórico de Lima reconocido como Patrimonio Cultural de la Humanidad por la UNESCO. Lima, Perú.

Panfichi H., A., Portocarrero S., (2004). Mundos Interiores: Lima 1850-1950. Lima: Centro de Investigación de la Universidad del Pacífico.

Rodríguez Larraín E., M. R. (2012). Estudio del Impacto de las Intervenciones en el Núcleo del Centro Históico de Lima, a partir de la Declaración de Patrimonio Cultural de la Humanidad, Tomos I-VI. Tesis para optar el grado de Maestro. Lima: UNI-FAUA.

UNESCO (1982). Declaración de México sobre los Políticas Culturales, Conferencia Mundial sobre Políticas Culturales. En UNESCO (Ed.). México D.F.: UNESCO.

UNESCO (1991). Convention Concerning the Protection of the World Cultural and Natural Heritage, World Heritago Committee, Fifteen Session. En UNESCO (Ed.),p. 31. Cartago: UNESCO.

UNESCO (2003). Convention Concerning the Protection of the World Cultural and Natural Heritafe, World Heritage Committee, Twenty-seventh Seccion. State of Conservation of World Heritage Properties Inscribed on the World Heritage List (p. 79). Paris: UNESCO.

UNESCO (2009). Convention Concerning the Protection of the World Cultural and Natural Heritage,World Heritage Commitee, Thirty-third Session. En UNESCO (Ed.) State of Conservation of World Heritage Properties Inscribed on the World Heritage List (pp. 248-351). Sevilla: UNESCO.

UNESCO (2010). Convention Concerning the Protection of the World Cultural and Natural Heritafe, World Heritage Committee, Thirty-four Session. En UNESCO (Ed.), State of Conservation of World Heritage Properties Inscribed on the World Heritage List (pp. 201-205). Brasilia: UNESCO.

UNESCO (2011). Convention Concerning the Protection of the World Cultural and Natural Heritage,World Heritage Commitee, Thirty-fifth Session. En UNESCO (Ed.), State of Conservation of World Heritage Properties Inscribed on the World Heritage List (pp. 279-282). Paris: UNESCO. 